\title{
Effects of gamma irradiation on the extraction
}

\section{properties of innovative stripping solvents for}

\section{$i$-SANEX/GANEX processes}

Eros Mossini ${ }^{a^{*}}$, Elena Macerata ${ }^{a}$, Nathalie Boubals ${ }^{b}$, Claude Berthon ${ }^{b}$, Marie-Christine

Charbonnel $^{b}$, Mario Mariani ${ }^{a}$

${ }^{a}$ Politecnico di Milano, Department of Energy - Nuclear Engineering Division, Piazza Leonardo da Vinci 32, 20133 Milano, Italy

${ }^{b}$ CEA, DES, ISEC, DMRC, University of Montpellier, Marcoule, F-30207 Bagnols-sur-Cèze, France.

KEYWORDS: Hydrophilic bis-triazolyl pyridine; Radiolysis; $i$-SANEX; EURO-GANEX.

ABSTRACT: Recovery of trivalent minor actinides or of all transuranium elements from highly active raffinate could be industrially achieved by innovative Selective ActiNide EXtraction (i-SANEX) and Grouped ActiNide EXtraction (GANEX) processes respectively. All chemicals involved in the partitioning of actinides must be resistant to acidic and radioactive environment, since hydrolysis and radiolysis can have huge impact on process safety and performance. In this work, the hydrolytic and radiolytic stability of two innovative hydrophilic complexing agents, 
triazolyl)]pyridine (PTT), have been investigated as they proved to be endowed with high actinides selectivity. In order to simulate the damage experienced at process conditions, the stripping solutions were aged in $\mathrm{HNO}_{3}$ for several weeks and $\gamma$-irradiated up to $200 \mathrm{kGy}$ with ${ }^{60} \mathrm{Co}$ sources. Batch liquid-liquid extraction tests were performed on fresh, aged and irradiated stripping solutions in order to verify whether ageing and $\gamma$-irradiation affect system performance. Furthermore, Nuclear Magnetic Resonance (NMR) analyses were carried out to ascertain the radiation-induced ligand degradation and consequent by-products formation. The stripping solutions manifested so exceptional performance and radiochemical stability, even at harsh process conditions, to demonstrate their industrial applicability to $i$-SANEX and GANEX processes.

\section{Introduction}

The accomplishment of nuclear fuel cycle sustainability and public acceptance should not disregard the improvement of natural resources exploitation and final repository footprint. For this reason, $\mathrm{U}$ and $\mathrm{Pu}$ recycling and minor actinides (MA: $\mathrm{Np}, \mathrm{Am}, \mathrm{Cm}$ ) Partitioning and Transmutation (P\&T) strategies have been conceived ${ }^{1-3}$. Until today, some hydrometallurgical processes, above all Plutonium and URanium EXtraction (PUREX) and its evolutions, have been successfully implemented at the industrial scale to retrieve $\mathrm{U}$ and $\mathrm{Pu}$ isotopes for the fabrication of MOX fuel ${ }^{4,5}$. In the last decades, great efforts have been devoted to the key and challenging issue of developing efficient processes to transmute trivalent MA after selective separation from lanthanides ( $\mathrm{Ln})$, as most of them are neutronic poisons ${ }^{6,7}$. Worldwide, promising hydrometallurgical processes have been proposed to overtake MA/Ln separation ${ }^{8-11}$. Furthermore, 
several joint research projects funded by the European Commission have been focused on developing compact and simplified separation strategies by limiting the number of cycles and devoting special attention to safety issues ${ }^{6,12}$. A promising process, named innovative-Selective ActiNide EXtraction ( $i$-SANEX), has been proposed for the recovery of trivalent MA directly from the PUREX raffinate ${ }^{13-15}$. Moreover, a more challenging concept has been introduced with the Grouped ActiNide EXtraction (EURO-GANEX) process, with the aim of homogeneously recovering in a single product solution all TRU regardless of their oxidation state ${ }^{16,17}$. In both cases, An and Ln are firstly extracted and separated from other elements contained in the acidic aqueous feed by means of one or more lipophilic ligands characterized by high An and Ln affinity along with satisfactory radiochemical stability, such as $N, N, N^{\prime}, N^{\prime}$-Tetraoctyl Diglycolamide (TODGA) ${ }^{14,18,19}$. In the second step, the An are selectively back-extracted into an aqueous phase by a hydrophilic complexing agent. In addition to the fulfilment of engineering performance constraints, i.e. affinity, fast kinetics and easy reversibility of An complexation, these watersoluble ligands should also comply with the $\mathrm{CHON}$ principle, i.e. being constituted only by $\mathrm{C}, \mathrm{H}$, $\mathrm{O}$ and $\mathrm{N}$ atoms to be incinerable without secondary solid waste production at the end of their life. Moreover, in view of the industrial application, they should be stable towards hydrolysis and radiolysis ${ }^{20}$. So far, several hydrophilic ligands based on the BTP (bis-triazinyl-pyridine), BTBP (bis-triazinyl-bipyridine) and BTPhen (bis-triazinyl-phenantroline) complexing cores have been developed ${ }^{21,22}$, such as 2,6-bis(5,6-di(sulfophenyl)-1,2,4-triazin-3-yl)pyridine $\left(\mathrm{SO}_{3}\right.$-Ph-BTP) ${ }^{23}$. Unfortunately, none of them has fully matched all the above-mentioned constraints.

In particular, the resistance towards hydrolysis and radiolysis is an undeniable key requirement in view of the industrial scale-up of advanced SNF partitioning processes due to the radioactive nuclides content ${ }^{24,25}$. In fact, radiolysis may induce production of ligand and diluent by-products, 
leading to consumption of the original ligand and to potential alteration of several properties ${ }^{26,27}$. Furthermore, radiation-induced alterations would undesirably affect not only the separation efficiency, but also the physico-chemical properties of the solvent ${ }^{28}$. In particular, the alteration of density and viscosity and the formation of precipitates and third phases has to be investigated, since they may compromise the hydrodynamic properties of the system or else the safety of the future reprocessing plants, due to malfunctioning at the pumps and at the centrifuges ${ }^{29-31}$. The stability of the TODGA organic solvent was exhaustively investigated. Now, the degradation mechanism, the main by-products and the impact on process performance are avowed ${ }^{32-35}$. While a wide literature exists about the radiochemical resistance of several lipophilic extractants developed for the 1-cycle SANEX ${ }^{36-38}$, few studies deal with the hydrophilic complexing agents. One of the most relevant ligands, 2,6-bis(5,6-di(sulfophenyl)-1,2,4-triazin-3-yl)pyridine ( $\mathrm{SO}_{3}-\mathrm{Ph}-\mathrm{BTP}$ ), showed a scarce stability in the homogeneous phase, and an opposite behaviour as a biphasic $\mathrm{SO}_{3}-\mathrm{Ph}-\mathrm{BTP} / \mathrm{TODGA}$ system ${ }^{39,40}$.

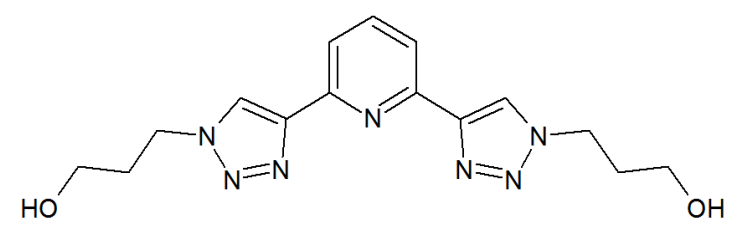

PTD

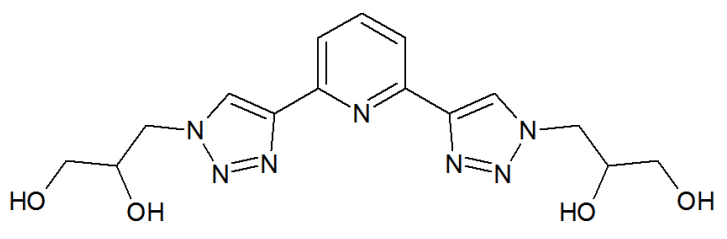

PTT

Figure 1 Molecular structures of PTD (left) and PTT (right)

In this paper, two hydrophilic complexing agents have been studied: 2,6-bis[1-(propan-1-ol)-1, 2,3-triazol-4-yl)]pyridine (PTD, see Figure 1, Left) and 2,6-bis[1-(propan-1,2-diol)-1,2,3-triazol4-yl)]pyridine (PTT, see Figure 1, Right). Their $\mathrm{N}_{3}$ chelating unit built on a central pyridine and arranged with two triazoles guarantees the selectivity for An, as already outlined in recent publications ${ }^{41-43}$. These $\mathrm{CHON}$ complexing agents proved to be outstanding candidates for An selective stripping in $i$-SANEX or EURO-GANEX processes. In particular, PTD was already 
successfully tested in an industrial-like single-stage centrifugal contactor device, proving its effectiveness in separating trivalent minor actinides from $\mathrm{Ln}^{44}$. Also hydrolytic and radiolytic stability of aqueous stripping solvents based on PTD or PTT have already been outlined, but still deserve further investigations ${ }^{45}$. The aim of this paper is to shine a light on this aspect. In order to simulate the radiolytic damage delivered at reprocessing conditions, stripping solutions containing

the hydrophilic ligand were irradiated at different absorbed doses by means of a ${ }^{60} \mathrm{Co}$ gamma source with $2.5 \mathrm{kGy} / \mathrm{h}$ dose rate and subsequently analysed. In order to distinguish the contribution of hydrolysis from radiolysis, aliquots of the same solutions were aged for the same length of time. Therefore, the results obtained with irradiated solutions have been compared with those obtained with fresh and aged solutions. The investigation has been mainly focused on assessing the performances of these irradiated solutions under $i$-SANEX and EURO-GANEX process conditions by means of batch liquid-liquid extraction tests. Furthermore, density, viscosity and acidity of the stripping solutions were measured before and after irradiation, in order to verify that no modification of physico-chemical properties occurred, possibly resulting in alterations of the system fluid-dynamics. Finally, the ligand degradation and consequent by-products formation have been ascertained by NMR spectroscopy.

Materials and Methods

Analytical grade reagents were purchased from Sigma Aldrich and used without further purification. In order to simulate the process feed, a simplified High Active Raffinate (HAR) solution was prepared by dissolving weighted amounts of $\mathrm{La}\left(\mathrm{NO}_{3}\right)_{3} \cdot 6 \mathrm{H}_{2} \mathrm{O}(99.99 \%$ purity), $\mathrm{Ce}\left(\mathrm{NO}_{3}\right)_{3} \cdot 6 \mathrm{H}_{2} \mathrm{O}(99.0 \%), \operatorname{Pr}\left(\mathrm{NO}_{3}\right)_{3} \cdot 6 \mathrm{H}_{2} \mathrm{O}(99.9 \%), \mathrm{Nd}\left(\mathrm{NO}_{3}\right)_{3} \cdot 6 \mathrm{H}_{2} \mathrm{O}(99.9 \%), \mathrm{Sm}\left(\mathrm{NO}_{3}\right)_{3} \cdot 6 \mathrm{H}_{2} \mathrm{O}$ (99.9\%), $\mathrm{Eu}\left(\mathrm{NO}_{3}\right)_{3} \cdot 5 \mathrm{H}_{2} \mathrm{O}(99.9 \%), \mathrm{Gd}\left(\mathrm{NO}_{3}\right)_{3} \cdot 6 \mathrm{H}_{2} \mathrm{O}(99.9 \%)$ and $\mathrm{Y}\left(\mathrm{NO}_{3}\right)_{3} \cdot 6 \mathrm{H}_{2} \mathrm{O}(99.8 \%)$ in 3 
mol/L $\mathrm{HNO}_{3}$ diluent. The feed was conveniently spiked with representative radiotracers. The solutions of ${ }^{152} \mathrm{EuCl}_{3}$ in $1 \mathrm{~mol} / \mathrm{L} \mathrm{HCl}$, used at Politecnico di Milano and at ATALANTE facility (CEA Marcoule) laboratories, were purchased from LEA-CERCA (France). The solution of ${ }^{241} \mathrm{Am}\left(\mathrm{NO}_{3}\right)_{3}$ in $1 \mathrm{~mol} / \mathrm{L} \mathrm{HNO}_{3}$, used at Politecnico di Milano, was supplied by Eurostandard $\mathrm{CZ}$ (Czech Republic). While the radioactive solutions containing ${ }^{239} \mathrm{Pu}(\mathrm{IV}),{ }^{241} \mathrm{Am}(\mathrm{III})$, and ${ }^{244} \mathrm{Cm}$ (III) used at CEA laboratory were prepared by dissolving weighed amounts of the respective oxides in $\mathrm{HNO}_{3}$, followed by careful purification by ion exchange chromatography and verification of the oxidation state by UV-Vis spectrophotometry, as elsewhere described ${ }^{46-48}$. In particular, the composition of these stock solutions was: $0.017 \%{ }^{238} \mathrm{Pu}, 96.91 \%{ }^{239} \mathrm{Pu}, 2.99 \%{ }^{240} \mathrm{Pu}, 0.065 \%{ }^{241} \mathrm{Pu}$, and $0.009 \%{ }^{242} \mathrm{Pu}$ for $\mathrm{Pu}, 98.74 \%{ }^{241} \mathrm{Am},<0.02 \%{ }^{242} \mathrm{Am}$, and $1.25 \%{ }^{243} \mathrm{Am}$ for Am, and mainly ${ }^{244} \mathrm{Cm}$ for $\mathrm{Cm}$. TODGA ligand was provided by the Institute for Nuclear Waste Disposal at Karlsruhe Institute of Technology, Germany. All the organic solvents used in this work were prepared by dissolving weighted quantities of extractant in kerosene with 5 vol.-\% 1-octanol to obtain $0.2 \mathrm{~mol} / \mathrm{L}$ TODGA concentration. PTD and PTT complexing agents were synthetised at Università di Parma according to the procedures elsewhere described ${ }^{41}$. Otherwise explicitly specified, all the stripping solutions studied in this work consisted of $0.08 \mathrm{~mol} / \mathrm{L}$ PTD or 0.15 $\mathrm{mol} / \mathrm{L}$ PTT in $0.44 \mathrm{~mol} / \mathrm{L} \mathrm{HNO}_{3}$, as optimized in a previous work ${ }^{41,44}$.

Ageing

Stock PTD and PTT stripping solutions were prepared, pre-equilibrated with the organic solvent and stored in $20 \mathrm{~mL}$ glass vials closed with a plastic lid and kept in the dark at lab temperature $\left(22^{\circ} \mathrm{C} \pm 2{ }^{\circ} \mathrm{C}\right)$. In order to evaluate the effect of ageing on extraction properties by means of batch stripping experiments, $300 \mu \mathrm{L}$ aliquots were subsampled from the stock solutions immediately after preparation and after 66 and 321 or 342 days. 


\section{Irradiation}

The PTD and PTT stripping solutions were stored in $4 \mathrm{~mL}$ glass vials closed with a plastic lid and sealed with Parafilm ${ }^{\circledR}$ in order to avoid sample leakage during irradiation. Between the preparation and the analysis, the samples were kept in the dark. If not explicitly specified, the stripping solutions were not pre-equilibrated with the organic solvent. The irradiations were performed at ambient temperature by $2.5 \mathrm{kGy} / \mathrm{h}$ dose rate ${ }^{60} \mathrm{Co}$ source. Even though the radiation damage received by the stripping solutions should mainly derive from alpha radiolysis, the irradiation was performed by gamma sources. This choice is usually justified by the technically simpler implementation of gamma irradiations and by the more conservative results with respect to alpha radiolysis ${ }^{27}$. At the end of the irradiation of the sample with highest absorbed dose, all samples were stored in the dark at $4{ }^{\circ} \mathrm{C} \pm 1{ }^{\circ} \mathrm{C}$ until liquid-liquid extraction experiments. Therefore, same thermal treatment was used for all samples. The same irradiation and storage procedures were employed with $0.08 \mathrm{~mol} / \mathrm{L}$ PTD solutions in $0.44 \mathrm{~mol} / \mathrm{L} \mathrm{DNO}_{3}$ for $\mathrm{NMR}$ investigation.

Density, viscosity and acidity measurement

Density measurements of fresh and irradiated PTD stripping solutions were performed by DMA $35 \mathrm{~N}$ Anton Paar portable density meter. The samples were kept in a thermostatic bath and analysed at temperatures of interest for the process, namely from 20 to $45^{\circ} \mathrm{C} \pm 0.1^{\circ} \mathrm{C}$, with $5^{\circ} \mathrm{C}$ temperature increments between each density measurement. An equilibration time of about 10 minutes was applied at each temperature step to enable the samples to reach the desired temperature. Each density value is averaged on ten measurements. The measuring uncertainty was estimated according to minimum mean square error method, considering the standard deviations of the acquired data and the measuring uncertainty associated to the instrument $\left( \pm 0.001 \mathrm{~g} / \mathrm{cm}^{3}\right)^{30,31,49}$. 
Viscosity measurements of fresh and irradiated PTD stripping solutions were performed by KPG-UBBELOHDE micro-viscometer with $0.32 \mathrm{~mm}$ diameter capillary. Also in this case, the above-described protocol was followed to analyse the samples at the temperatures of interest for the process, between $20^{\circ} \mathrm{C}$ and $45^{\circ} \mathrm{C} \pm 0.1{ }^{\circ} \mathrm{C}$. A digital stopwatch with $1 / 100 \mathrm{~s}$ time resolution was used to measure the efflux time, afterwards corrected by the Hagenback factor and then averaged on five measurements. Finally, the kinematic viscosity and the associated uncertainty are calculated as described in a previous work ${ }^{30,31,49}$.

Acidity measurements of fresh and irradiated PTD and PTT stripping solutions were performed by potentiometric titration with $0.1 \mathrm{~mol} / \mathrm{L} \mathrm{NaOH}$ standard solution, using Titrando $905 \mathrm{Metrohm}$.

Solvent extraction experiment

Details about the solvent extraction experimental protocol and equipment are reported in the Supplementary Information (SI). All batch stripping experiments were performed by contacting equal volumes of aqueous stripping solution and the TODGA-based organic solvent, previously loaded from an aqueous feed and scrubbed with $0.5 \mathrm{~mol} / \mathrm{L} \mathrm{HNO}_{3}{ }^{15}$. In order to understand the radiolytic effect on the extraction properties, the results obtained with irradiated stripping solutions are compared with those of samples aged for the same period of time. Two different aqueous feed solutions suitably spiked with radiotracers were used to load the organic solvent: one merely consisting of $3 \mathrm{~mol} / \mathrm{L} \mathrm{HNO}_{3}$ (feed $I$ ) and another one more realistic and representative containing, coherently with the PUREX raffinate composition, $2.49 \mathrm{~g} / \mathrm{L}$ of yttrium and $\mathrm{Ln}$ (from lanthanum to gadolinium, see Table 1) in $3 \mathrm{~mol} / \mathrm{L} \mathrm{HNO}_{3}$ (feed II). Trace amounts of selected radionuclides (about $10 \mathrm{kBq} / \mathrm{mL}$ each) were added: ${ }^{239} \mathrm{Pu}(\mathrm{IV}),{ }^{241} \mathrm{Am}(\mathrm{III})$ and ${ }^{244} \mathrm{Cm}$ (III) as representative of An and ${ }^{152} \mathrm{Eu}(\mathrm{III})$ for $\mathrm{Ln}$. After the tests, the activity concentrations of ${ }^{241} \mathrm{Am}$ and ${ }^{152} \mathrm{Eu}$ in aqueous and organic phases were quantified by $\gamma$-spectrometry, exploiting the $\gamma$-lines at $59.5 \mathrm{keV}$ and 121.8 
$\mathrm{keV}$, respectively. In view of $\alpha$-spectrometry analysis, two aliquots of aqueous phases and three aliquots of organic phases were sampled and evaporated to dryness on steel planchets. Consequently, the activity concentrations of ${ }^{239} \mathrm{Pu}(\mathrm{IV}),{ }^{241} \mathrm{Am}$ (III) and ${ }^{244} \mathrm{Cm}$ (III) were determined by $\alpha$-spectrometry, exploiting the lines at $5156.6 \mathrm{keV}, 5442.8 \mathrm{keV}$ and $5762.7 \mathrm{keV}$ respectively. Since ${ }^{241} \mathrm{Am}$ was measured both by $\alpha$ and $\gamma$ spectrometry, it was used to normalize ${ }^{244} \mathrm{Cm}$ and ${ }^{239} \mathrm{Pu}$ activity concentrations, in order to minimize their mass balances errors. The concentrations of stable Y and Ln were determined by Inductively Coupled Plasma - Mass Spectrometry (ICP-MS). Table 1 Composition of feed II used in the extraction experiments.

\begin{tabular}{llll}
\hline Element & $\begin{array}{l}\text { Concentration } \\
(\mathrm{kBq} / \mathrm{mL})\end{array}$ & Element & $\begin{array}{l}\text { Concentration } \\
(\mathrm{mg} / \mathrm{L})\end{array}$ \\
\hline${ }^{244} \mathrm{Cm}(\mathrm{III})$ & 10 & $\mathrm{Y}$ & 72 \\
${ }^{239} \mathrm{Pu}(\mathrm{IV})$ & 10 & $\mathrm{La}$ & 288 \\
${ }^{241} \mathrm{Am}(\mathrm{III})$ & 10 & $\mathrm{Ce}$ & 710 \\
${ }^{152} \mathrm{Eu}(\mathrm{III})$ & 10 & $\mathrm{Pr}$ & 259 \\
& & $\mathrm{Nd}$ & 921 \\
& & $\mathrm{Sm}$ & 155 \\
& & $\mathrm{Eu}$ & 34 \\
& & $\mathrm{Gd}$ & 53 \\
\hline
\end{tabular}

The performance of irradiated stripping solutions was evaluated by comparing distribution ratios ( $D_{M}$, where $M$ is the metal) and separation factors $\left(S F_{M 1 / M 2}\right.$, where $M 1$ and $M 2$ are different cations) with those obtained with un-irradiated reference solutions. The efficiency is evaluated by the $D_{M}$, calculated as the ratio between the concentration of $M$ in the organic and in the aqueous phases. Whereas, the selectivity for An towards $L n$ is expressed by the $S F_{L n / A n}$, defined as the ratio between 
$D_{L n}$ and $D_{A n}$. The activity balance was checked and the overall accuracy in the determination of $D_{M}$ was estimated to be within $\pm 10 \%$ for distribution ratios between 0.01 and 100 .

NMR analysis

All solutions to be analysed by NMR were prepared with $0.08 \mathrm{~mol} / \mathrm{L}$ PTD in deuterated nitric acid and eventually irradiated by $2.5 \mathrm{kGy} / \mathrm{h}$ dose rate ${ }^{60} \mathrm{Co}$ source at $100 \mathrm{kGy}$. Signal identification was accomplished by ${ }^{1} \mathrm{H}$ and ${ }^{13} \mathrm{C}$ NMR analyses on a fresh PTD solution. Confirmation of signal assignment was achieved by 2D homo and heteronuclear NMR. All analyses were performed by introducing a pure nitromethane capillary in the NMR tube, in order to have a reference signal. Nitromethane ${ }^{1} \mathrm{H},{ }^{13} \mathrm{C}$ and ${ }^{15} \mathrm{~N}$ signals were set at $4.40,63.22$ and 0 ppm respectively ${ }^{50}$.

Results and Discussion

Physico-chemical properties of irradiated solutions

In previous works, the physico-chemical properties of aqueous diluent $(0.25$ and $0.5 \mathrm{~mol} / \mathrm{L}$ $\mathrm{HNO}_{3}$ ) were investigated after gamma irradiation of pure solutions or in presence of the organic diluent (namely kerosene with 5 vol.-\% 1-octanol) ${ }^{30,31}$. Both diluents manifested a suitable physico-chemical stability with respect to radiolysis. Those experiments revealed that they should withstand the radiolytic degradation without alterations that could compromise safety and performances of the process ${ }^{30,31}$. For this reason, some physico-chemical properties of the stripping solutions containing the complexing agent, PTD, were studied. Radiolysis was simulated by means of irradiation with the $2.5 \mathrm{kGy} / \mathrm{h}$ dose rate ${ }^{60} \mathrm{Co}$ source. First of all, the irradiated solutions remained transparent, without any precipitate. Density, viscosity and acidity were measured and the results are reported in the following Figure 2, Figure 3 and Figure 4 respectively. Moreover, the acidity measurement was accomplished also with fresh and irradiated PTT stripping solutions. 


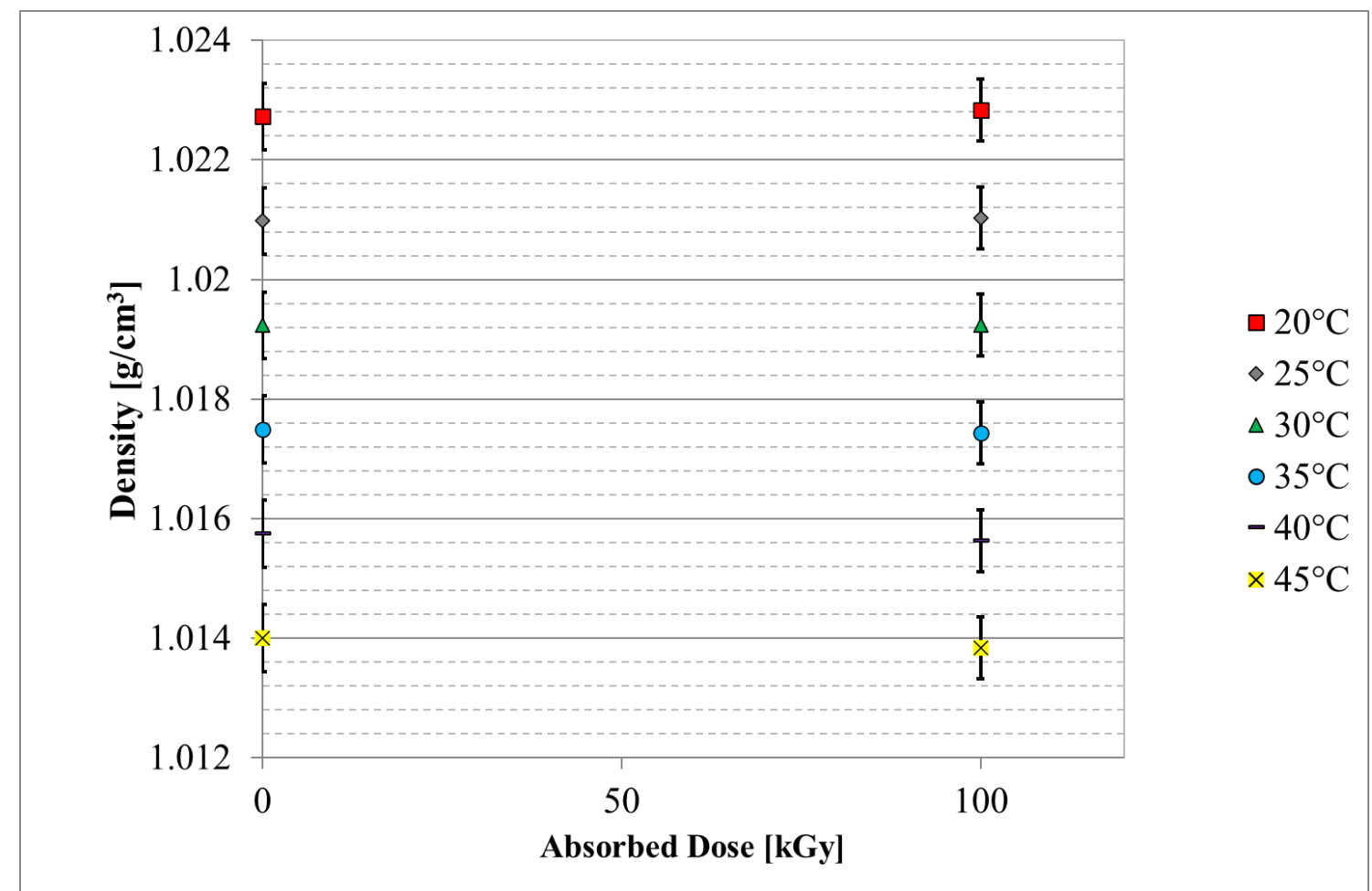

Figure 2 Density of fresh and irradiated $0.08 \mathrm{~mol} / \mathrm{L} \mathrm{PTD} \mathrm{in} 0.44 \mathrm{~mol} / \mathrm{L} \mathrm{HNO}$. The irradiation was performed with the high dose rate ${ }^{60} \mathrm{Co}$ source $(2.5 \mathrm{kGy} / \mathrm{h})$ up to absorbed dose of $100 \mathrm{kGy}$. The analyses were performed at different temperatures from $20^{\circ} \mathrm{C}$ to $45^{\circ} \mathrm{C}$. 


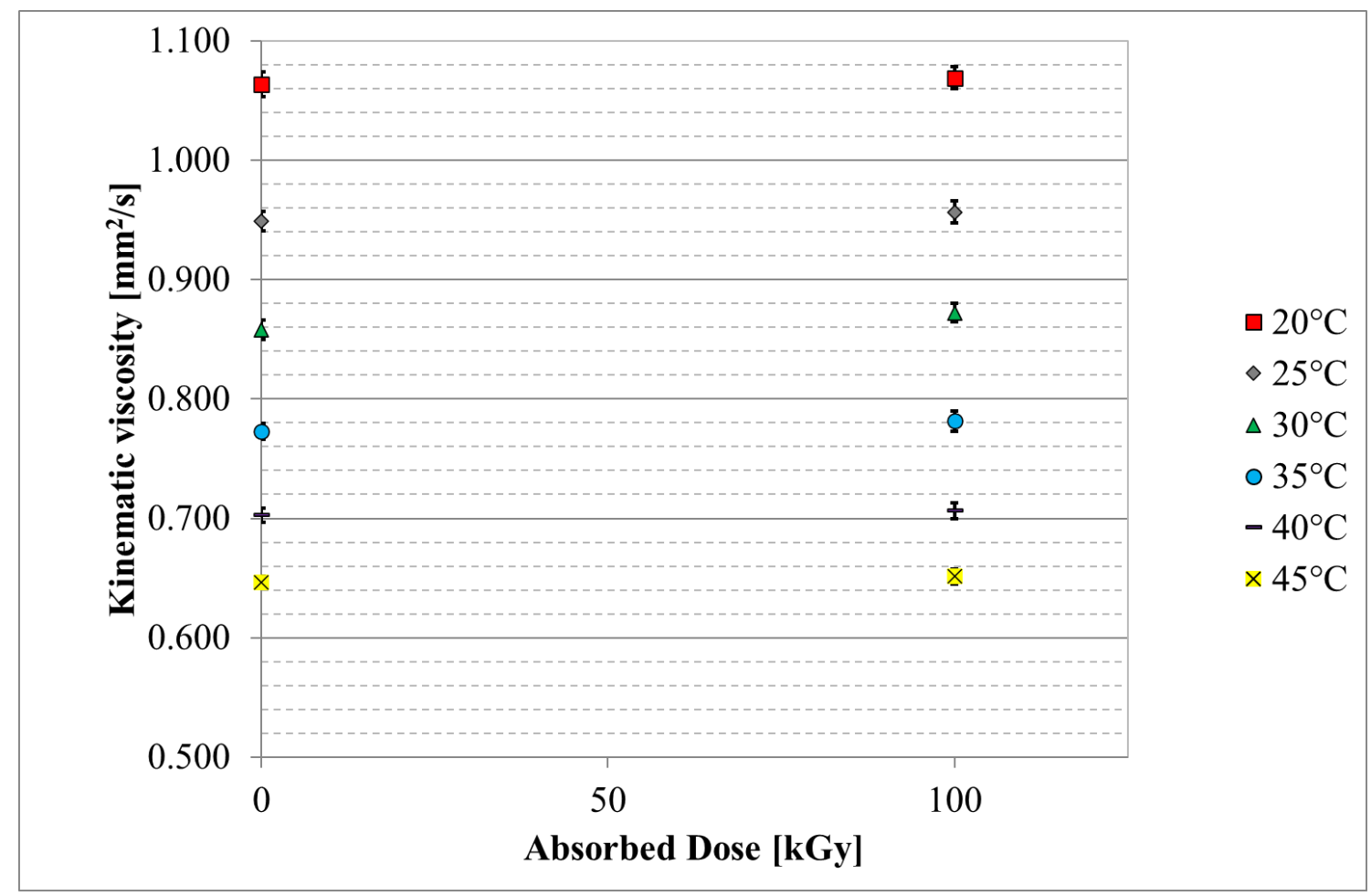

Figure 3 Viscosity of fresh and irradiated $0.08 \mathrm{~mol} / \mathrm{L} \mathrm{PTD} \mathrm{in} 0.44 \mathrm{~mol} / \mathrm{L} \mathrm{HNO}_{3}$. The irradiation was performed with the high dose rate ${ }^{60} \mathrm{Co}$ source $(2.5 \mathrm{kGy} / \mathrm{h})$ up to absorbed dose of $100 \mathrm{kGy}$. The analyses were performed at different temperatures from $20^{\circ} \mathrm{C}$ to $45^{\circ} \mathrm{C}$. 


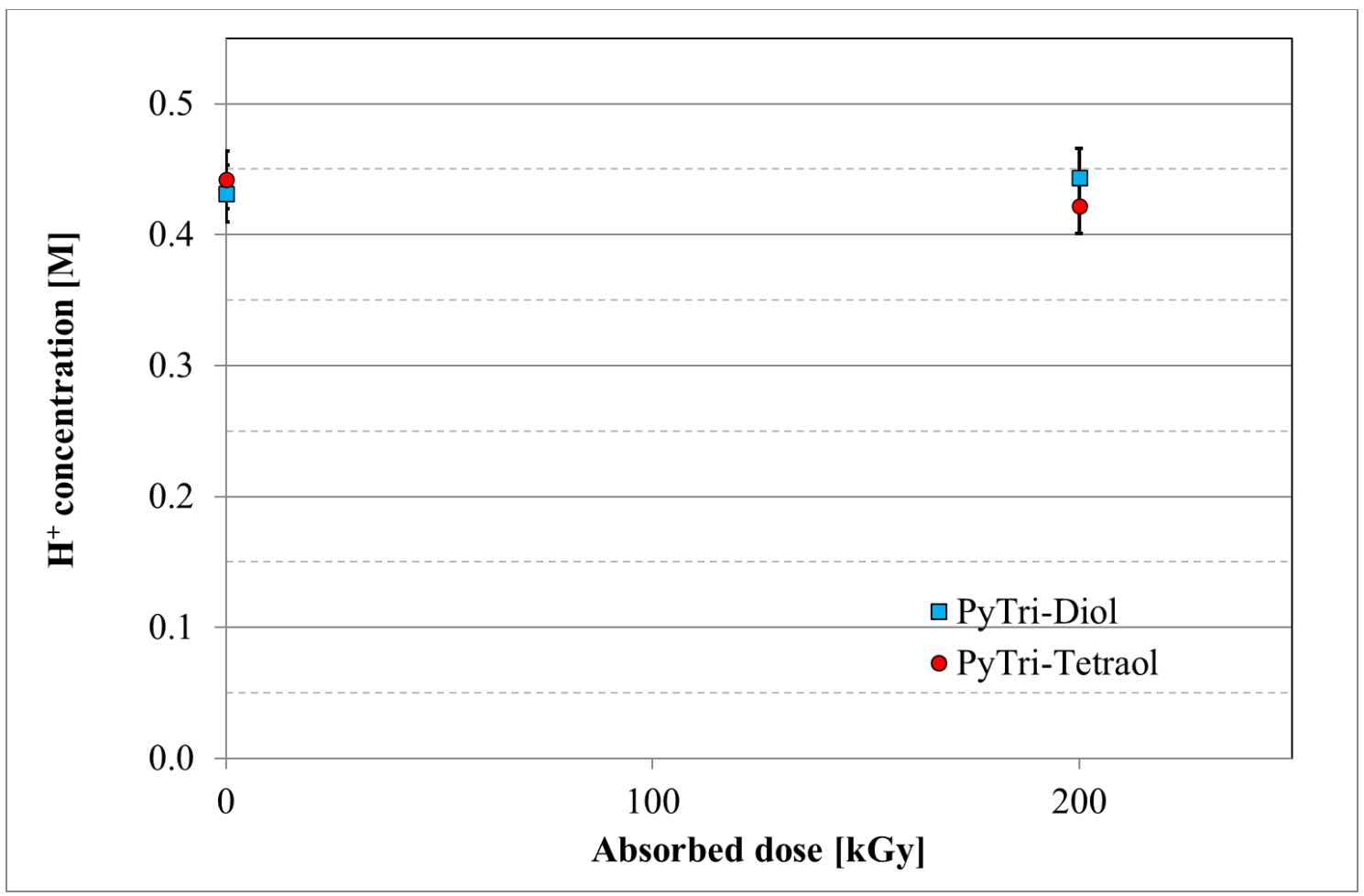

Figure 4 Acidity of fresh and irradiated $0.08 \mathrm{~mol} / \mathrm{L}$ PTD (blue square markers) and $0.15 \mathrm{~mol} / \mathrm{L}$ PTT (red circle markers) in $0.44 \mathrm{~mol} / \mathrm{L} \mathrm{HNO}_{3}$. The irradiation was performed with the high dose rate ${ }^{60} \mathrm{Co}$ source $(2.5 \mathrm{kGy} / \mathrm{h})$ up to absorbed dose of $200 \mathrm{kGy}$.

No evidence of radiation-induced alteration of density, viscosity and acidity was found. In fact, deviations from the values of the fresh solutions lie within the limit of experimental uncertainty and cannot be ascribed to the radiolytic effect. These experiments outlined that also the solutions containing the complexing agent are stable towards radiations in terms of preservation of density, viscosity and acidity. This result is very promising for the future implementation at an industrial scale. Actually, alteration of these properties could affect the ligand performances, due to films formation or acidity changes. Moreover, the safety of the process could be compromised not only by the formation of dangerous by-product (i.e. hydrogen or explosive compounds), but also by precipitates, density and viscosity changes, which may impact on fluid dynamics of the system and on centrifugal contactor safety operation. 


\section{Extracting properties of aged solutions}

With the purpose of assessing the ageing effect on their extracting properties, PTD and PTT stripping solutions were aged up to 321 and 342 days respectively. The aged stripping solutions remained transparent, without any precipitate. They were contacted with the fresh TODGA-based organic solvent, previously loaded from feed I spiked with ${ }^{241} \mathrm{Am}(\mathrm{III})$ and ${ }^{152} \mathrm{Eu}(\mathrm{III})$ and scrubbed with $0.5 \mathrm{~mol} / \mathrm{L} \mathrm{HNO}_{3}$. The results of these experiments are compared with those obtained with fresh stripping solutions. As it could be inferred from the results reported in Figure 5, both PTD and PTT ligands maintain their extraction performance at least up to the extreme ageing period of about one year. In fact, the distribution ratio of $\mathrm{Am}(\mathrm{III})$ is steadily below unity and that of $\mathrm{Eu}(\mathrm{III})$ above unity, so that the $S F_{E u / A m}$ is almost constant along the whole ageing period considered, within the experimental uncertainty. These results promisingly demonstrate that both PTD and PTT stripping solutions are stable towards ageing in nitric acid solutions at least up to one year. 

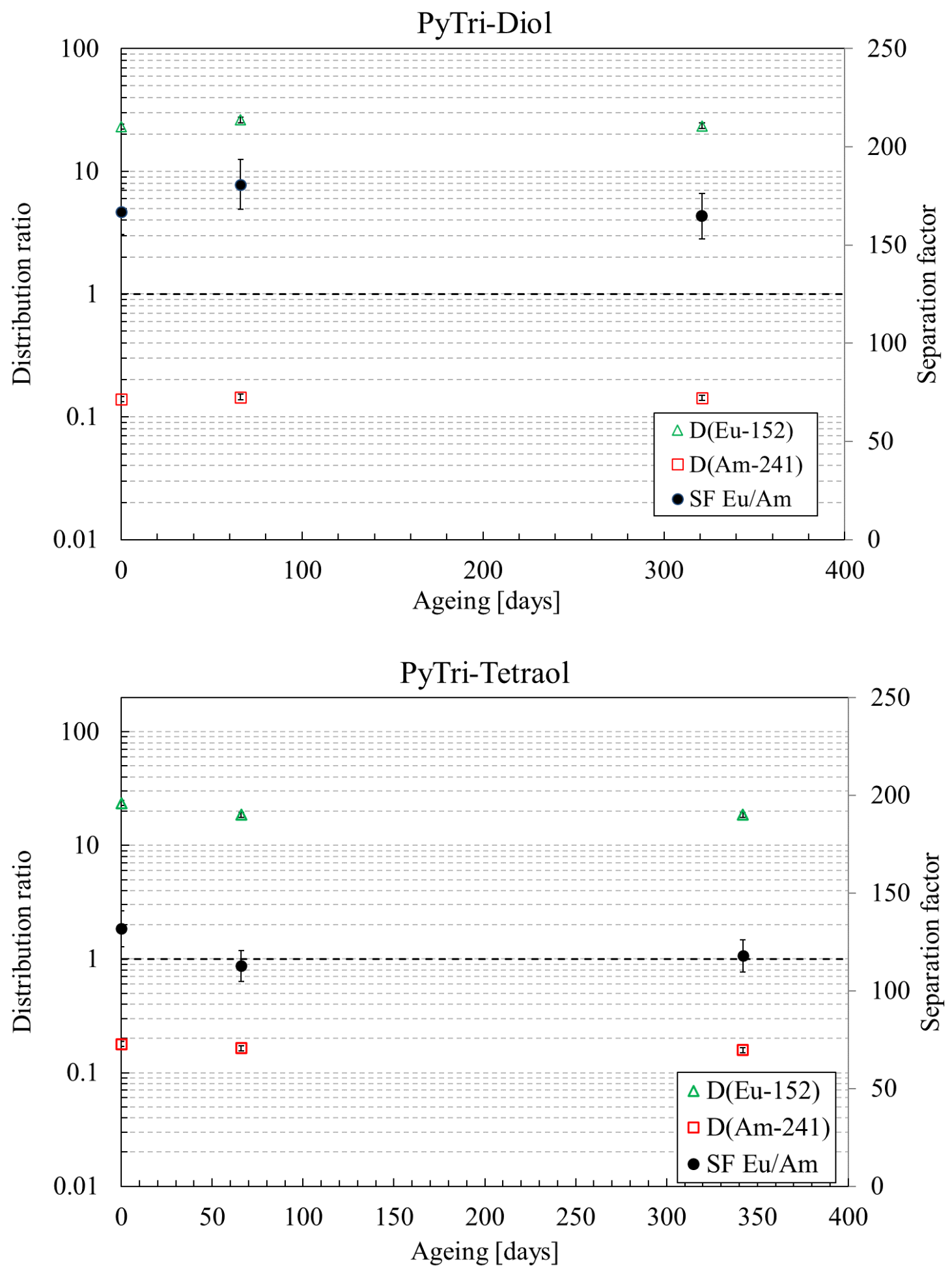

Figure 5 Distribution ratios of trivalent $\mathrm{Am}$ and $\mathrm{Eu}$ as a function of aqueous stripping phase ageing. Distribution ratios uncertainty bars are within the marker size. Organic phase: $0.2 \mathrm{~mol} / \mathrm{L}$ TODGA in kerosene with 5 vol.-\% 1-octanol loaded from feed I spiked with ${ }^{241} \mathrm{Am}(\mathrm{III})$ and ${ }^{152} \mathrm{Eu}(\mathrm{III})$ and 
scrubbed with $0.5 \mathrm{~mol} / \mathrm{L} \mathrm{HNO}_{3}$. Aqueous stripping phases: $0.08 \mathrm{~mol} / \mathrm{L}$ PTD (top) or $0.15 \mathrm{~mol} / \mathrm{L}$ PTT (bottom) in $0.44 \mathrm{~mol} / \mathrm{L}^{-\mathrm{HNO}_{3}}$. The stripping phases were aged in the dark at ambient temperature $\left(22^{\circ} \mathrm{C} \pm 2^{\circ} \mathrm{C}\right)$ for 66 and 321 or 342 days.

\section{Extracting properties of irradiated solutions}

Several experiments were performed in order to verify whether gamma irradiation affects the ligand performance of irradiated PTD and PTT stripping solutions. These solutions were irradiated by $2.5 \mathrm{kGy} / \mathrm{h}$ dose rate ${ }^{60} \mathrm{Co}$ source at different absorbed doses up to $500 \mathrm{kGy}$. First of all, it has to be pointed out that the irradiated solutions remained transparent, without any precipitate, for whatever irradiation condition. In order to perform the extraction experiments, the irradiated stripping solutions were contacted with the TODGA-based organic solvent, previously loaded from different feeds conveniently spiked with trace amounts of An and Ln representatives. Distribution ratios and separation factors obtained with irradiated stripping solutions were compared with those of samples aged for the same period of time.

A preliminary investigation aimed at obtaining a first information on the performances of PTD after irradiation up to $200 \mathrm{kGy}$ was reported in a previous work ${ }^{41}$. The experiments were performed by contacting the irradiated stripping solutions with the TODGA-based organic solvent loaded from the simplest feed solution (feed I) spiked with ${ }^{241} \mathrm{Am}$ and ${ }^{152} \mathrm{Eu}$. The distribution ratios of both radionuclides do not show evident alterations at increasing absorbed dose with respect to not irradiated stripping solution: $D_{A m}$ remains significantly smaller than unity and $D_{E u}$ greater than unity. Consequently, the $\mathrm{Eu} / \mathrm{Am}$ separation proves to be effective at least up to $200 \mathrm{kGy}$. These encouraging results are consistent with previously mentioned analyses and suggests an unprecedented radiolytic resistance of the PTD based stripping phase ${ }^{51}$. In order to get more 
complete information on the performance of irradiated PTD and PTT stripping solutions, further irradiation and extraction experiments have been carried out and are herein reported.

The PTD and PTT stripping solutions were irradiated by HDR ${ }^{60} \mathrm{Co}$ source at different absorbed doses up to $500 \mathrm{kGy}$. These solutions were contacted with the fresh TODGA-based organic solvent loaded from feed I spiked with ${ }^{241} \mathrm{Am}$ and ${ }^{152} \mathrm{Eu}$. The results of these stripping experiments are reported in the following Figure 6. As it could be evidenced, the distribution ratios of PTD are almost constant until the exceptional absorbed dose of $200 \mathrm{kGy}$, in confirmation of previous results, but sharply decrease at $500 \mathrm{kGy}$. Since this effect is more important for ${ }^{152} \mathrm{Eu}$ than for ${ }^{241} \mathrm{Am}$, the Eu/Am separation factor worsen by increasing the absorbed dose. Reassuringly, the process requirements are still fully met even at the extreme $500 \mathrm{kGy}$ absorbed dose, since $D_{E u}$ remains largely above the unity. Concerning PTT, the distribution ratios undergo a similar decreasing trend, merely steeper at lower absorbed doses. Also in this case, the process requirements are still fully fulfilled, even if the effect on $D_{E u}$ is more evident and leads to a reduction of $S F_{E u / A m}$ with the absorbed dose. 

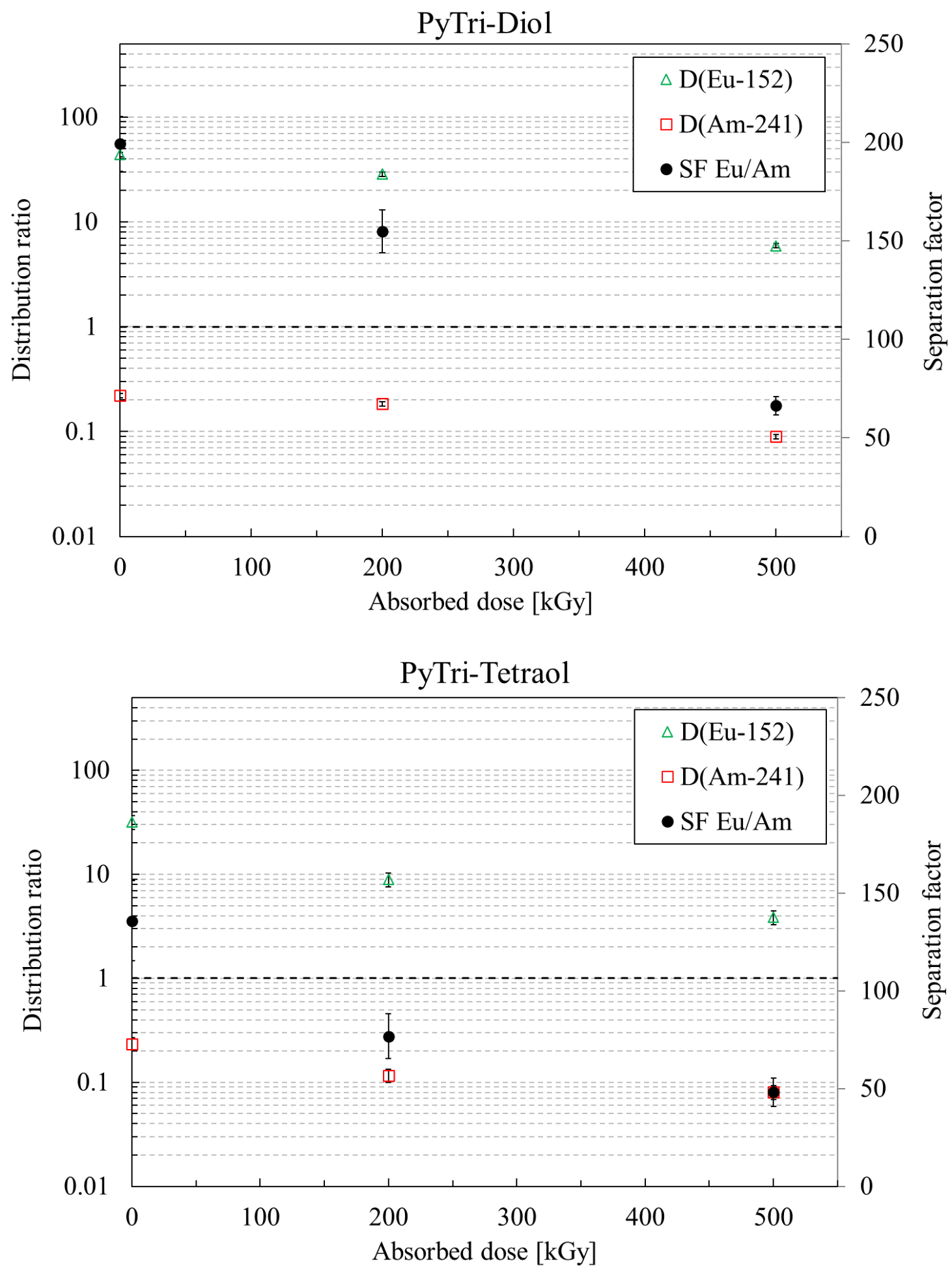

Figure 6 Distribution ratios of trivalent Am and Eu as a function of absorbed dose. Distribution ratios uncertainty bars are within the marker size. Organic phase: $0.2 \mathrm{~mol} / \mathrm{L}$ TODGA in kerosene with 5 vol.-\% 1-octanol loaded from feed I spiked with ${ }^{241} \mathrm{Am}(\mathrm{III})$ and ${ }^{152} \mathrm{Eu}(\mathrm{III})$ and scrubbed 
with $0.5 \mathrm{~mol} / \mathrm{L} \mathrm{HNO}_{3}$. Aqueous stripping phases: $0.08 \mathrm{~mol} / \mathrm{L}$ PTD (top) or $0.15 \mathrm{~mol} / \mathrm{L}$ PTT (bottom) in $0.44 \mathrm{~mol} / \mathrm{L} \mathrm{HNO}_{3}$. The irradiation of the stripping phase alone was performed with 2.5 $\mathrm{kGy} / \mathrm{h}$ dose rate ${ }^{60} \mathrm{Co}$ source up to absorbed dose of $500 \mathrm{kGy}$.

Another solvent extraction experiment was performed with the PTD and PTT stripping solutions, pre-equilibrated with the TODGA-based organic solvent before irradiation by $2.5 \mathrm{kGy} / \mathrm{h}$ dose rate ${ }^{60} \mathrm{Co}$ source at different absorbed doses up to $200 \mathrm{kGy}$. After the irradiation, these solutions were contacted with the fresh TODGA-based organic solvent loaded from feed I spiked with ${ }^{241} \mathrm{Am}$ and ${ }^{152} \mathrm{Eu}$. The results of these stripping experiments are reported in the following Figure 7.

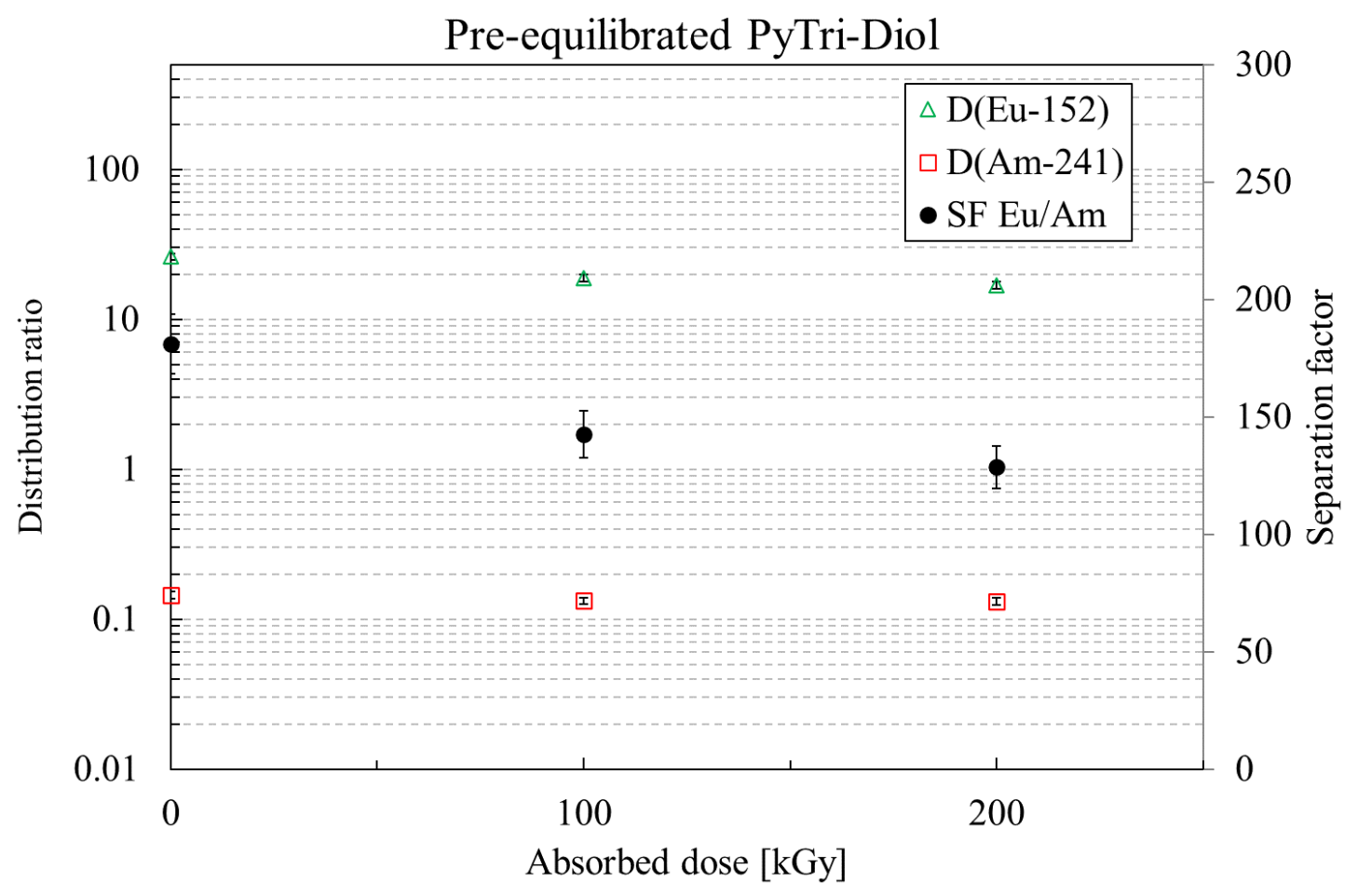




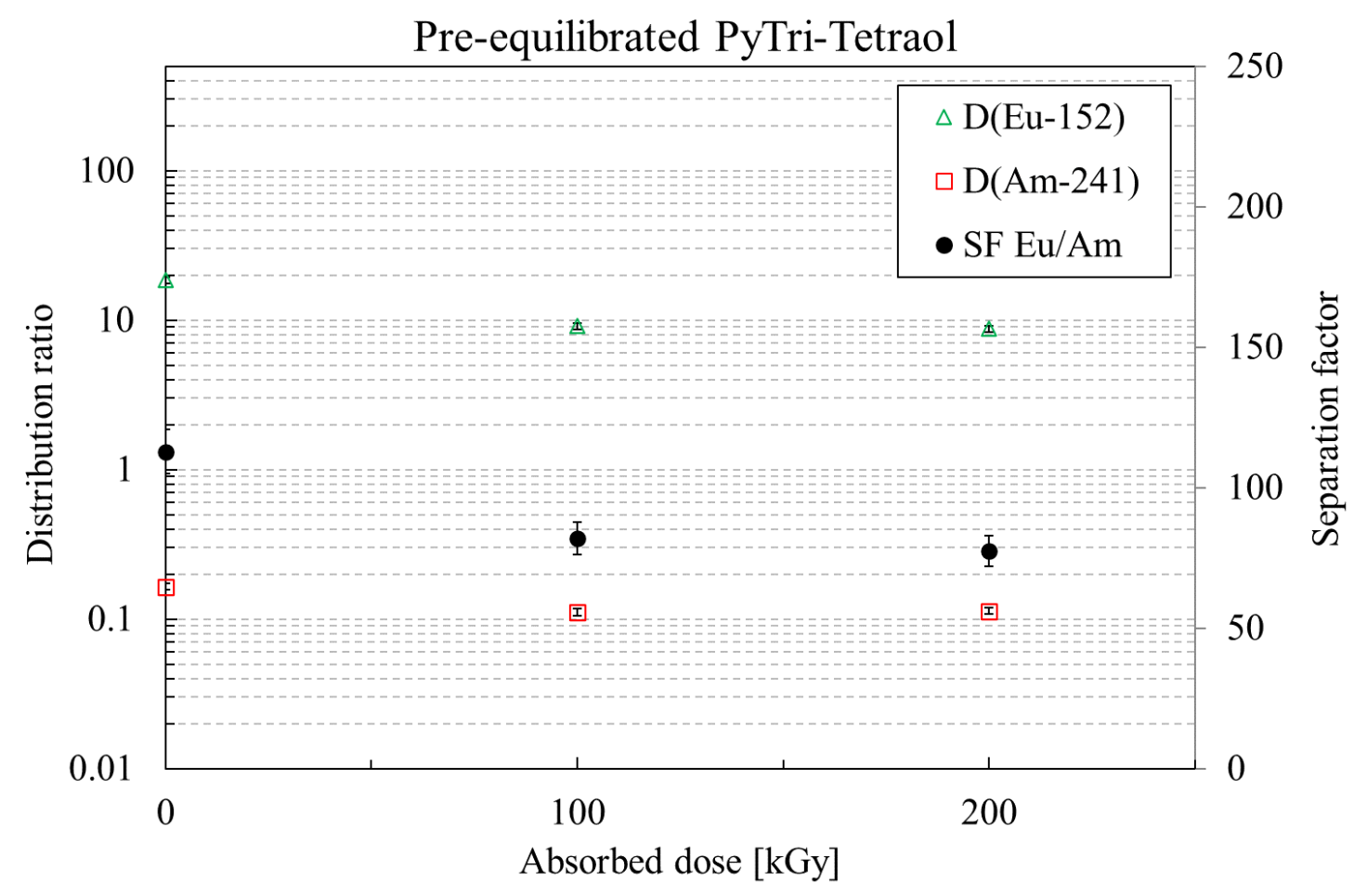

Figure 7 Distribution ratios of trivalent $\mathrm{Am}$ and $\mathrm{Eu}$ as a function of absorbed dose. Distribution ratios uncertainty bars are within the marker size. Organic phase: 0.2 mol/L TODGA in kerosene with 5 vol.-\% 1-octanol loaded from feed I spiked with ${ }^{241} \mathrm{Am}(\mathrm{III})$ and ${ }^{152} \mathrm{Eu}(\mathrm{III})$ and scrubbed with $0.5 \mathrm{~mol} / \mathrm{L} \mathrm{HNO}_{3}$. Aqueous stripping phases: $0.08 \mathrm{~mol} / \mathrm{L}$ PTD (top) or $0.15 \mathrm{~mol} / \mathrm{L}$ PTT (bottom) in $0.44 \mathrm{~mol} / \mathrm{L} \mathrm{HNO}_{3}$. The irradiation of the stripping phase alone was performed with 2.5 $\mathrm{kGy} / \mathrm{h}$ dose rate ${ }^{60} \mathrm{Co}$ source up to absorbed dose of $200 \mathrm{kGy}$, after pre-equilibration with the organic solvent.

Concerning PTD, $D_{A m}$ is almost constant in the whole dose range considered, further confirming the previous results. On the contrary, $D_{E u}$ slightly decrease as the absorbed dose increase, so that the Eu/Am separation factor tends to degrade. The distribution ratios and the Eu/Am separation factor of the PTT stripping solution undergo a similar decreasing trend as well, merely visible also for $D_{A m}$. Anyhow, the process requirements are still fully satisfied both with PTD and PTT stripping solutions. 
In order to assess if radiolysis has an impact on PTD and PTT selectivity for Am towards all Ln present in the PUREX raffinate, a more complex and representative feed (feed II) spiked with ${ }^{241} \mathrm{Am}(\mathrm{III})$ and ${ }^{152} \mathrm{Eu}(\mathrm{III})$ was employed. PTD and PTT stripping solutions were irradiated with 2.5 $\mathrm{kGy} / \mathrm{h}$ dose rate ${ }^{60} \mathrm{Co}$ source up to $200 \mathrm{kGy}$. The results are reported in Figure 8 as a function of the absorbed dose. For all the measured samples, a good agreement was found between distribution coefficients of ${ }^{152} \mathrm{Eu}$ and stable europium, even if the former is present at tracer concentration while the second at approximately $45 \mathrm{mg} / \mathrm{L}$. 

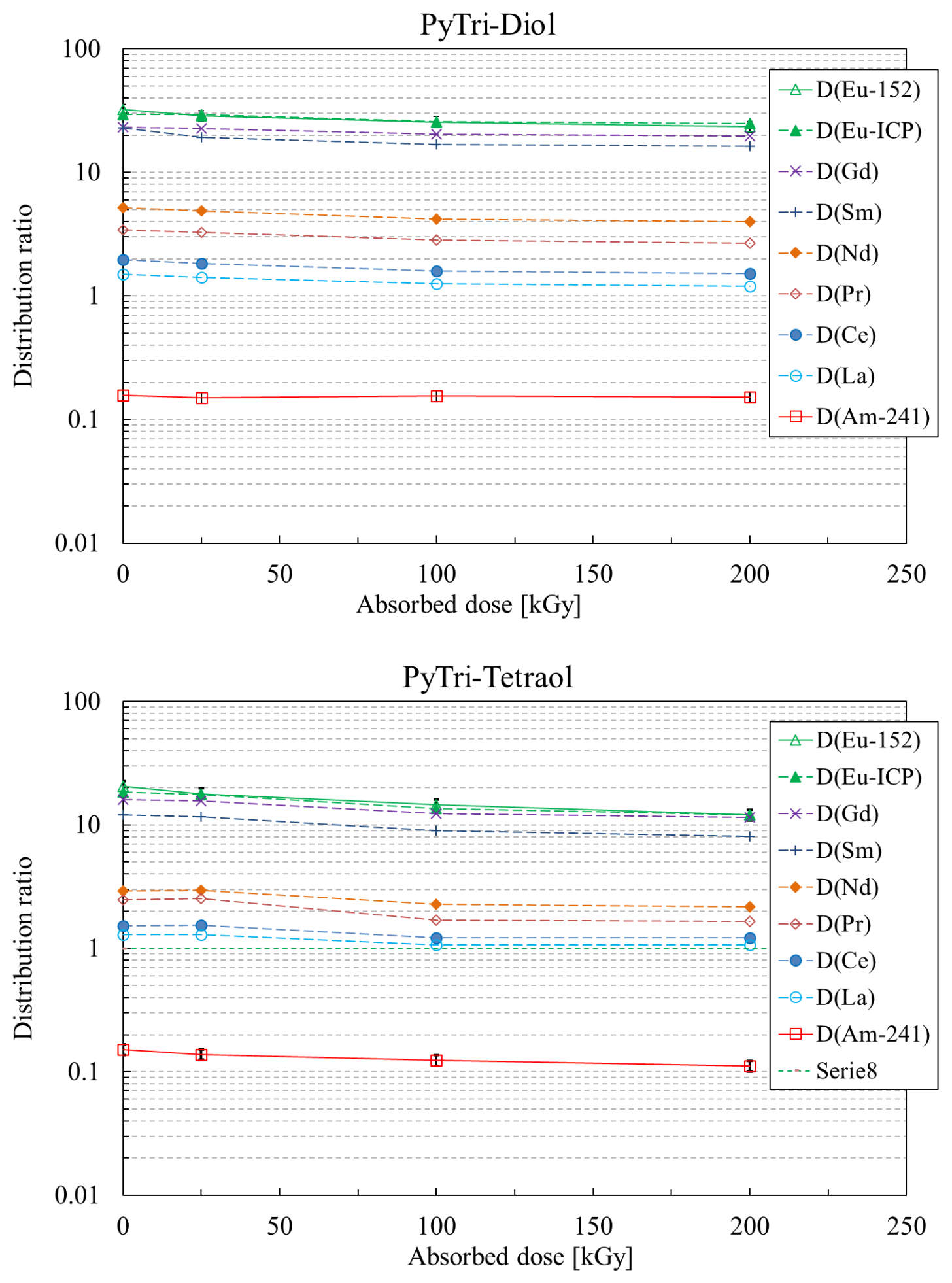

Figure 8 Distribution ratios of trivalent Am and $\mathrm{Ln}$ as a function of absorbed dose. The uncertainty bars are within the marker size. Organic phase: $0.2 \mathrm{~mol} / \mathrm{L}$ TODGA in kerosene with 5 vol.- $\% 1$ octanol loaded from feed II spiked with ${ }^{241} \mathrm{Am}(\mathrm{III})$ and ${ }^{152} \mathrm{Eu}(\mathrm{III})$ and scrubbed with $0.5 \mathrm{~mol} / \mathrm{L}$ 
$\mathrm{HNO}_{3}$. Aqueous stripping phases: $0.08 \mathrm{~mol} / \mathrm{L} \mathrm{PTD}$ (top) or $0.15 \mathrm{~mol} / \mathrm{L}$ PTT (bottom) in $0.44 \mathrm{~mol} / \mathrm{L} \mathrm{HNO}_{3}$. The irradiation was performed with $2.5 \mathrm{kGy} / \mathrm{h}$ dose rate ${ }^{60} \mathrm{Co}$ source up to absorbed dose of $200 \mathrm{kGy}$.

In the case of PTD, the distribution ratios of trivalent $\mathrm{Ln}$ and ${ }^{241} \mathrm{Am}$ are almost constant with the absorbed dose. In fact, the alteration of these values is comprised within the associated uncertainty. Moreover, Am distribution ratio remains significantly below the unity and $\mathrm{D}_{\mathrm{Ln}}$ above the unity. However, lanthanum is the most back-extracted $\mathrm{Ln}$, the $\mathrm{SF}_{\mathrm{La} / \mathrm{Am}}$ of about 10 is consistent with the process requirements. Similar results were achieved with PTT even if, in this case, a slight reduction of distribution ratios with the absorbed dose could be inferred for all cations, as already outlined by the abovementioned results. These preliminary batch experiments clearly showed that PTD and PTT based stripping solutions could provide satisfactory selectivity for Am over the Ln family in backward extraction mode even at elevated absorbed doses (up to $200 \mathrm{kGy}$ ). These outstanding results, already obtained with trace concentrations of metal ions, have now been corroborated with the organic phase loaded with real concentration of $\operatorname{Ln}(f e e d I I)$.

In order to assess if irradiated PTD and PTT based stripping solutions could be used in $i$-SANEX and GANEX processes, a series of experiments was performed with the TODGA-based organic solvent loaded from feed I and feed II, spiked with ${ }^{241} \mathrm{Am}(\mathrm{III}),{ }^{244} \mathrm{Cm}(\mathrm{III}),{ }^{239} \mathrm{Pu}(\mathrm{IV}),{ }^{152} \mathrm{Eu}(\mathrm{III})$ tracers, and scrubbed with $0.5 \mathrm{~mol} / \mathrm{L} \mathrm{HNO}_{3}$. Before the solvent extraction experiments, the PTD and PTT stripping solutions were irradiated with $2.5 \mathrm{kGy} / \mathrm{h}$ dose rate ${ }^{60} \mathrm{Co}$ source up to $200 \mathrm{kGy}$. The concentration of stable Ln was not assessed because of unavailability of active ICP-MS technique in the ATALANTE facility. Anyway, all results collected so far would confirm that no appreciable alteration of $D_{L n}$ values is expected with respect to the data reported in Figure $8^{44}$. The results of the stripping experiments obtained by contacting PTD and PTT solutions with the 
organic solvent loaded from feed $I$ and feed II are reported in Figure 9 and Figure 10 respectively. The distribution ratios of ${ }^{241} \mathrm{Am}(\mathrm{III})$ and ${ }^{244} \mathrm{Cm}$ (III) were measured in order to verify the affinity of the ligands for trivalent actinides and, consequently, the applicability to $i$-SANEX process. On the other hand, the affinity between ligands and actinides in different oxidation states was assessed by determining the ${ }^{239} \mathrm{Pu}(\mathrm{IV})$ distribution ratios. Since $\mathrm{Ln}$ were not measured, ${ }^{152} \mathrm{Eu}(\mathrm{III})$ was assumed as their representative. The uncertainty bars included in the graphic take into account the mass balance error and the measuring uncertainty. In the case of ${ }^{152} \mathrm{Eu}$ and ${ }^{241} \mathrm{Am}$ the uncertainty is approximately $10 \%$, in the case of ${ }^{244} \mathrm{Cm}$ and ${ }^{239} \mathrm{Pu}$ is around $20 \%$.

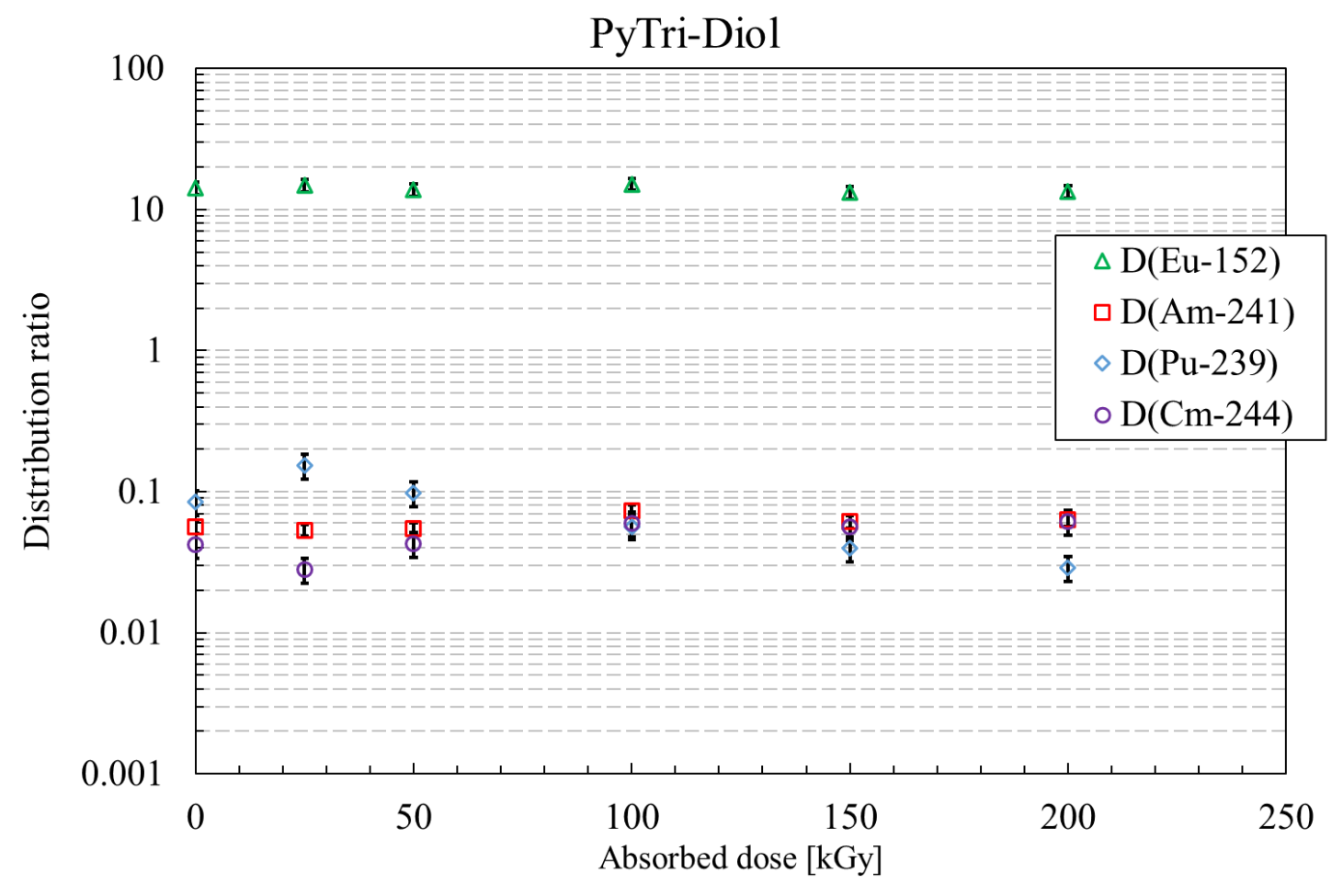




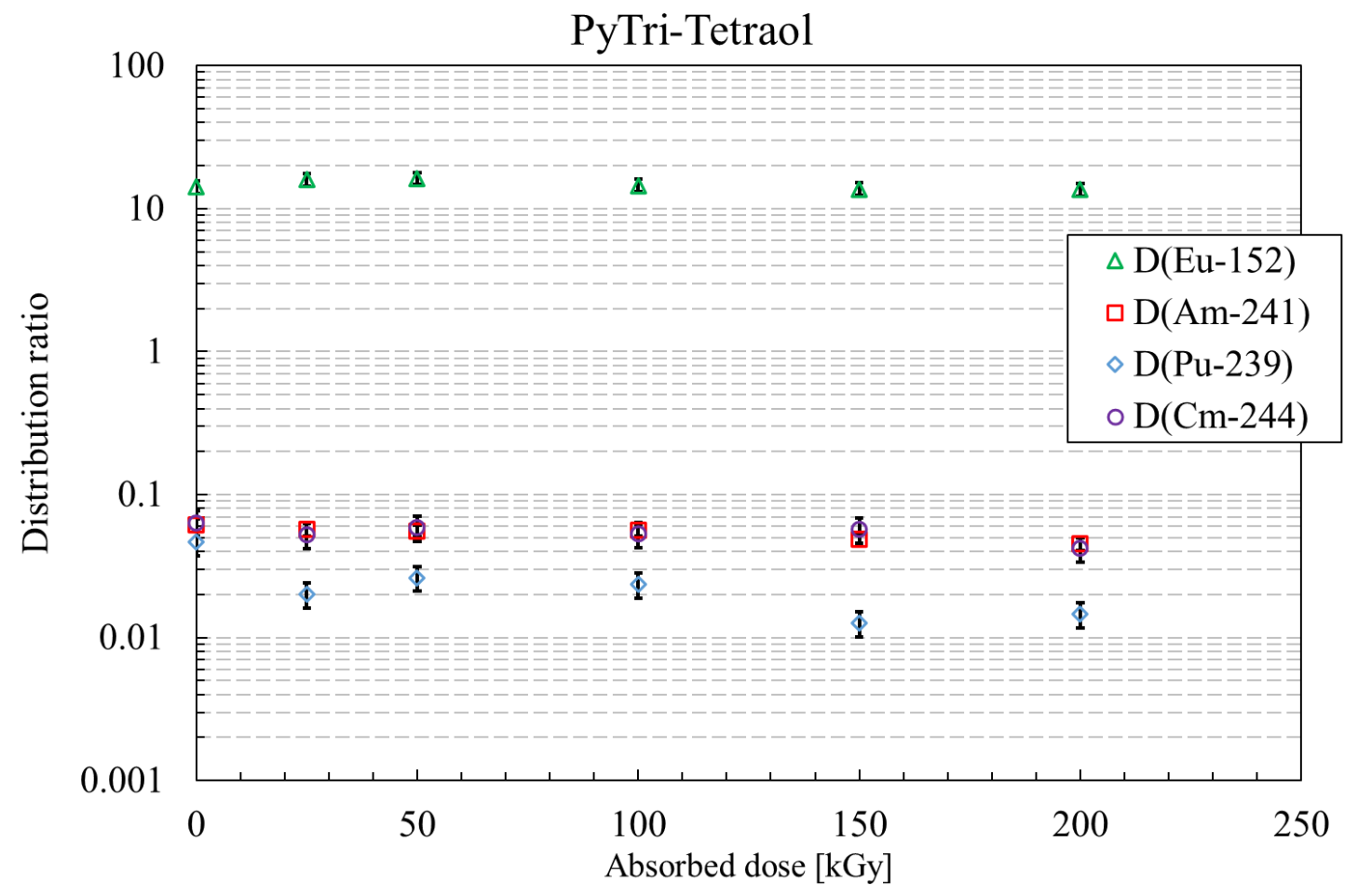

Figure 9 Distribution ratios of ${ }^{241} \mathrm{Am}(\mathrm{III}),{ }^{244} \mathrm{Cm}(\mathrm{III}),{ }^{239} \mathrm{Pu}(\mathrm{IV}),{ }^{152} \mathrm{Eu}(\mathrm{III})$ as a function of absorbed dose. The uncertainty bars of $D_{A m}$ and $D_{E u}$ are within the marker size. Organic phase: $0.2 \mathrm{~mol} / \mathrm{L}$ TODGA in kerosene with 5 vol.-\% 1-octanol loaded from feed I spiked with ${ }^{241} \mathrm{Am}$ (III), ${ }^{244} \mathrm{Cm}(\mathrm{III}),{ }^{239} \mathrm{Pu}(\mathrm{IV}),{ }^{152} \mathrm{Eu}(\mathrm{III})$ at $3 \mathrm{~mol} / \mathrm{L} \mathrm{HNO}_{3}$ and scrubbed with $0.5 \mathrm{~mol} / \mathrm{L} \mathrm{HNO}_{3}$. Aqueous stripping phases: $0.08 \mathrm{~mol} / \mathrm{L}$ PTD (top) or $0.15 \mathrm{~mol} / \mathrm{L}$ PTT (bottom) in $0.44 \mathrm{~mol} / \mathrm{L} \mathrm{HNO}_{3}$. The irradiation was performed with $2.5 \mathrm{kGy} / \mathrm{h}$ dose rate ${ }^{60} \mathrm{Co}$ source up to absorbed dose of $200 \mathrm{kGy}$. 

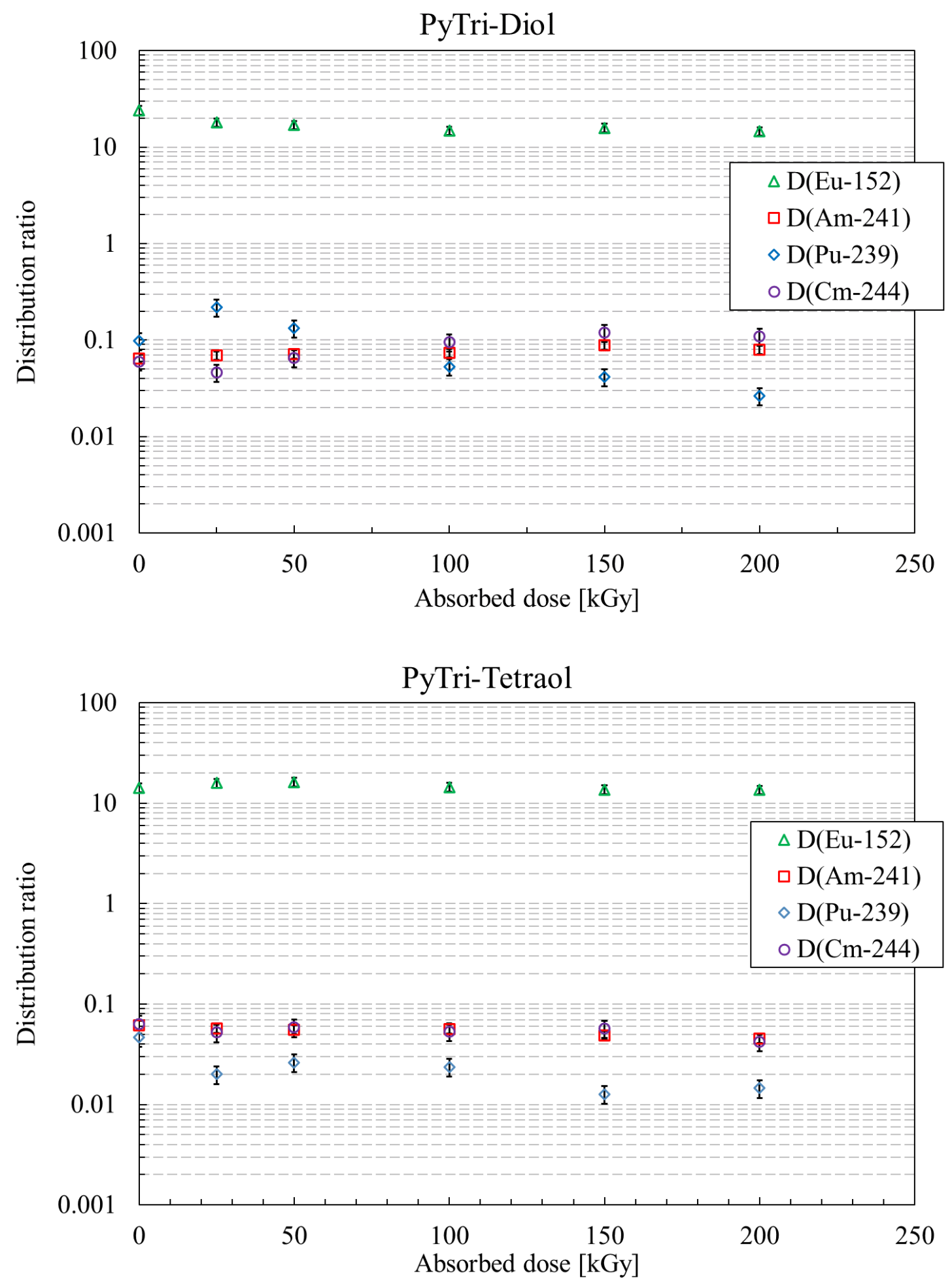

Figure 10 Distribution ratios of ${ }^{241} \mathrm{Am}(\mathrm{III}),{ }^{244} \mathrm{Cm}(\mathrm{III}),{ }^{239} \mathrm{Pu}(\mathrm{IV}),{ }^{152} \mathrm{Eu}(\mathrm{III})$ as a function of absorbed dose. The uncertainty bars of $D_{A m}$ and $D_{E u}$ are within the marker size. Organic phase: 0.2 mol/L TODGA in kerosene with 5 vol.-\% 1-octanol loaded from feed II spiked with ${ }^{241} \mathrm{Am}(\mathrm{III})$, 
${ }^{244} \mathrm{Cm}(\mathrm{III}),{ }^{239} \mathrm{Pu}(\mathrm{IV}),{ }^{152} \mathrm{Eu}(\mathrm{III})$ at $3 \mathrm{~mol} / \mathrm{L} \mathrm{HNO}_{3}$ and scrubbed with $0.5 \mathrm{~mol} / \mathrm{L} \mathrm{HNO}_{3}$. Aqueous stripping phases: $0.08 \mathrm{~mol} / \mathrm{L}$ PTD (top) or $0.15 \mathrm{~mol} / \mathrm{L}$ PTT (bottom) in $0.44 \mathrm{~mol} / \mathrm{L} \mathrm{HNO}_{3}$. The irradiation was performed with $2.5 \mathrm{kGy} / \mathrm{h}$ dose rate ${ }^{60} \mathrm{Co}$ source up to absorbed dose of $200 \mathrm{kGy}$.

The results obtained with feed I are comparable with those of feed II, as they show very similar distribution ratios trends. Concerning PTD, as it could be observed, the ${ }^{152} \mathrm{Eu}$ distribution ratio is rather constant and above 1. At the same time, the distribution ratios of trivalent MA are consistently below 1 up to $200 \mathrm{kGy}$, so that the separation factors between trivalent Eu and MA are always extremely high, proficiently fulfilling $i$-SANEX process requirements. Moreover, the distribution ratios of ${ }^{241} \mathrm{Am}$ and ${ }^{244} \mathrm{Cm}$ manifest a similar trend with the absorbed dose. Concerning the applicability to the GANEX process, even if ${ }^{239} \mathrm{Pu}(\mathrm{IV})$ shows a little more fluctuating trend with the absorbed dose, the goal of TRU/Ln separation is successfully reached at least up to the exceptional absorbed dose of $200 \mathrm{kGy}$. The results obtained with irradiated PTT stripping solutions are similar to those of PTD. In this case, the separation factors between europium and MA are slightly lower. Moreover, ${ }^{239} \mathrm{Pu}$ distribution ratio seems to slightly decrease with the absorbed dose. In any case, also the PTT based stripping solvent manifests promising stability towards radiolysis. Even if the preservation of the promising selectivity for MA and TRU of irradiated PyTri-based stripping solvents was successfully demonstrated by liquid-liquid extraction experiments, it is important to understand the degradation mechanism in terms of quantification of ligand consumption and by-products formation.

Degradation of irradiated solutions

As already outlined in the literature, information about ligand degradation cannot be just gathered from alteration of distribution ratios of irradiated solutions. In fact, the radiolytic byproducts may have extraction properties markedly different from those of the pristine ligand ${ }^{52}$. In 
order to shine a light on the hydrolytic and radiolytic degradation of PTD based stripping solutions, a preliminary study on irradiated solutions has been carried out by NMR. In particular, a PTD solution was irradiated at integrated dose of $100 \mathrm{kGy}$ by a ${ }^{60} \mathrm{Co}$ source characterized by $2.5 \mathrm{kGy} / \mathrm{h}$ dose rate. A suitable non-irradiated stripping solution was freshly prepared and kept as reference in order to discriminate the possible effect of ageing and radiolysis.

NMR spectroscopy was employed with the purpose of confirming the preliminary results already obtained by ESI-MS and FT-Raman, whose results have already been published elsewhere ${ }^{51}$. The NMR spectra are reported in SI. No radiation-induced signals shifts were observable in ${ }^{1} \mathrm{H}-\mathrm{NMR}$ spectrum of irradiated PTD if compared with the fresh one. Furthermore, several new signals could be recognised in the spectrum of the irradiated sample, but the relative areas of these new signals were few $\%$ of the original ones, in agreement with former FT-Raman results. The ${ }^{13} \mathrm{C}-\mathrm{NMR}$ spectra of fresh and irradiated ligand solutions did not show any radiation-induced alteration. Similarly, homonuclear (gCOSY) and heteronuclear (gHMBCAD and gHSQCAD) 2D NMR spectroscopic analyses were performed, and no differences were evidenced. This means that the by-products concentration is below few $\mathrm{mmol} / \mathrm{L}$, in agreement with all other results. It was concluded that the PyTri chelating unit should not present neither hydrolytic nor radiolytic degradation. This is coherent with FT-Raman results, since the intensities of the Raman bands referred to vibrational modes of the aromatic moiety of the ligands remain unchanged ${ }^{51}$. Consequently, radiation-induced modification may reasonably occur just on the alkyl chains, rather than on the chelating unit.

\section{Conclusion}

The results of this research contribute to demonstrate the efficacy of the PyTri-based stripping solutions in the cutting-edge hydrometallurgical separative strategies for the reprocessing of An 
from the SNF. In fact, these complexing agents proved to fulfil the main requirements for future industrial implementation: i) $\mathrm{CHON}$ principle, ii) feasible scale-up of the synthesis, iii) selectivity for MA and TRU and low affinity for Ln and other cations of the PUREX raffinate, iv) fast stripping kinetics, v) reversibility of An retention, vi) no hydrodynamic problems such as third phases and precipitates, vii) stability towards hydrolysis and radiolysis. In particular, it was confirmed that gamma irradiated PTD and PTT based stripping solutions are promisingly stable towards radiolysis. In fact, their excellent selectivity for MA and TRU over Ln is maintained up to the extreme absorbed dose of $500 \mathrm{kGy}$, not only with trace concentration cations but also with an organic solvent loaded from a more realistic synthetic PUREX raffinate. Moreover, density, viscosity and acidity, that are physico-chemical properties relevant for the process implementation, are also preserved. The NMR analytical technique further proved PTD resistance towards radiation damage.

Further investigations are on-going, in order to obtain information essential for the industrial implementation of PyTri-based stripping solutions, such as: i) metal loading capacity, ii) impact of temperatures reached in the industrial devices on the extracting properties, iii) study of degradation mechanism by HPLC-DAD and HPLC-MS analyses and iv) identification and confirmation of the degradation by-product structures by HPLC-MS ${ }^{2}$. The synthesis and analytical characterization of the proposed by-products will be essential for the definitive confirmation of the radiolytic degradation path and will allow to evaluate their impact on the extracting efficiency.

\section{ASSOCIATED CONTENT}

Supporting Information. Details about the solvent extraction experimental protocol and equipment and NMR spectra are reported in the Supplementary Information (SI). 
The following files are available free of charge.

SI (PDF)

\section{AUTHOR INFORMATION}

\section{Corresponding Author}

* Any correspondence should be addressed to Eros Mossini, Phone.: +39 022399 6395; e-mail address: eros.mossini@polimi.it.

\section{Author Contributions}

The manuscript was written through contributions of all authors. All authors have given approval to the final version of the manuscript. All authors contributed equally.

\section{Funding Sources}

This work has been supported by the EU-FP7 TALISMAN (Grant no. 323300), EU-FP7

SACSESS (Grant no. 323282) and H2020-GENIORS (Grant no. 755171) projects and the Italian Ministry of Education, University and Research.

\section{ACKNOWLEDGMENT}

The authors wish to thank Gammatom Srl for the stripping solutions irradiation.

\section{REFERENCES}

(1) International Atomic Energy Agency. Assessment of Partitioning Processes for Transmutation of Actinides - TECDOC-1648; IAEA: Vienna, 2010.

(2) Poinssot, C.; Bourg, S.; Ouvrier, N.; Combernoux, N.; Rostaing, C.; Vargas-Gonzalez, M.; 
Bruno, J. Assessment of the Environmental Footprint of Nuclear Energy Systems. Comparison between Closed and Open Fuel Cycles. Energy 2014, 69, 199-211. https://doi.org/10.1016/j.energy.2014.02.069.

(3) Poinssot, C.; Bourg, S.; Boullis, B. Improving the Nuclear Energy Sustainability by Decreasing Its Environmental Footprint. Guidelines from Life Cycle Assessment Simulations. Prog. Nucl. Energy 2016, 92, 234-241. https://doi.org/10.1016/j.pnucene.2015.10.012.

(4) IAEA. Management of Reprocessed Uranium - Current Status and Future Prospects TECDOC-1529; 2007.

(5) Herbst, R. S.; Baron, P.; Nilsson, M. Standard and Advanced Separation: PUREX Processes for Nuclear Fuel Reprocessing. In Advanced Separation Techniques for Nuclear Fuel Reprocessing and Radioactive Waste Treatment; Elsevier Inc., Ed.; 2011; pp 141-175. https://doi.org/10.1533/9780857092274.2.141.

(6) Modolo, G.; Geist, A.; Miguirditchian, M. Minor Actinide Separations in the Reprocessing of Spent Nuclear Fuels: Recent Advances in Europe. In Reprocessing and Recycling of Spent Nuclear Fuel; Taylor, R., Ed.; Elsevier Inc., 2015; pp 245-287. https://doi.org/10.1016/B978-1-78242-212-9.00010-1.

(7) Nash, K. L.; Nilsson, M. Introduction to the Reprocessing and Recycling of Spent Nuclear Fuels. In Reprocessing and Recycling of Spent Nuclear Fuel; Taylor, R., Ed.; Elsevier Inc., 2015; pp 3-25. https://doi.org/10.1016/B978-1-78242-212-9.00001-0.

(8) Gelis, A. V.; Lumetta, G. J. Actinide Lanthanide Separation Process - ALSEP. Ind. Eng. 
Chem. Res. 2014. https://doi.org/10.1021/ie403569e.

(9) Lumetta, G. J.; Gelis, A. V.; Carter, J. C.; Niver, C. M.; Smoot, M. R. The ActinideLanthanide Separation Concept. Solvent Extr. Ion Exch. 2014. https://doi.org/10.1080/07366299.2014.895638.

(10) Nilsson, M.; Nash, K. L. Review Article: A Review of the Development and Operational Characteristics of the TALSPEAK Process. Solvent Extraction and Ion Exchange. 2007. https://doi.org/10.1080/07366290701634636.

(11) Koma, Y.; Watanabe, M.; Nemoto, S.; Tanaka, Y. Trivalent F-Element Intra-Group Separation by Solvent Extraction with Cmpo-Complexant System. J. Nucl. Sci. Technol. 1998. https://doi.org/10.1080/18811248.1998.9733833.

(12) Modolo, G.; Wilden, A.; Geist, A.; Magnusson, D.; Malmbeck, R. A Review of the Demonstration of Innovative Solvent Extraction Processes for the Recovery of Trivalent Minor Actinides from PUREX Raffinate. Radiochimica Acta. 2012. https://doi.org/10.1524/ract.2012.1962.

(13) Geist, A.; Modolo, G.; Wilden, A.; Kaufholz, P. Minor Actinide Separation: Simplification of the Diamex-Sanex Strategy by Means of Novel Sanex Processes. In International Nuclear Fuel Cycle Conference, GLOBAL 2013: Nuclear Energy at a Crossroads; 2013.

(14) Modolo, G.; Wilden, A.; Kaufholz, P.; Bosbach, D.; Geist, A. Development and Demonstration of Innovative Partitioning Processes (i-SANEX and 1-Cycle SANEX) for Actinide Partitioning. Prog. Nucl. Energy 2014, 72, 107-114. https://doi.org/10.1016/j.pnucene.2013.07.021. 
(15) Wilden, A.; Modolo, G.; Kaufholz, P.; Sadowski, F.; Lange, S.; Sypula, M.; Magnusson, D.; Müllich, U.; Geist, A.; Bosbach, D. Laboratory-Scale Counter-Current Centrifugal Contactor Demonstration of an Innovative-SANEX Process Using a Water Soluble BTP. Solvent Extr. Ion Exch. 2015. https://doi.org/10.1080/07366299.2014.952532.

(16) Taylor, R.; Carrott, M.; Galan, H.; Geist, A.; Hères, X.; Maher, C.; Mason, C.; Malmbeck, R.; Miguirditchian, M.; Modolo, G.; Rhodes, C.; Sarsfield, M.; Wilden, A. The EUROGANEX Process: Current Status of Flowsheet Development and Process Safety Studies. Procedia Chem. 2016. https://doi.org/10.1016/j.proche.2016.10.073.

(17) Malmbeck, R.; Magnusson, D.; Bourg, S.; Carrott, M.; Geist, A.; Hérès, X.; Miguirditchian, M.; Modolo, G.; Müllich, U.; Sorel, C.; Taylor, R.; Wilden, A. Homogenous Recycling of Transuranium Elements from Irradiated Fast Reactor Fuel by the EURO-GANEX Solvent Extraction Process. Radiochim. Acta 2019. https://doi.org/10.1515/ract-2018-3089.

(18) Ansari, S. A.; Pathak, P.; Mohapatra, P. K.; Manchanda, V. K. Chemistry of Diglycolamides: Promising Extractants for Actinide Partitioning. Chem. Rev. 2012, 112 (3), 1751-1772. https://doi.org/10.1021/cr200002f.

(19) Sasaki, Y.; Sugo, Y.; Suzuki, S.; Tachimori, S. THE NOVEL EXTRACTANTS, DIGLYCOLAMIDES, FOR THE EXTRACTION OF LANTHANIDES AND ACTINIDES IN HNO 3 - n -DODECANE SYSTEM. Solvent Extr. Ion Exch. 2001, 19 (1), 91-103. https://doi.org/10.1081/SEI-100001376.

(20) Bourg, S.; Hill, C.; Caravaca, C.; Rhodes, C.; Ekberg, C.; Taylor, R.; Geist, A.; Modolo, G.; Cassayre, L.; Malmbeck, R.; Harrison, M.; de Angelis, G.; Espartero, A.; Bouvet, S.; 
Ouvrier, N. ACSEPT_Partitioning Technologies and Actinide Science: Towards Pilot Facilities in Europe. Nucl. Eng. Des. 2011, 241 (9), 3427-3435. https://doi.org/10.1016/j.nucengdes.2011.03.011.

(21) Panak, P. J.; Geist, A. Complexation and Extraction of Trivalent Actinides and Lanthanides by Triazinylpyridine N -Donor Ligands. Chem. Rev. 2013, 113 (2), 1199-1236. https://doi.org/10.1021/cr3003399.

(22) Lewis, F. W.; Harwood, L. M.; Hudson, M. J.; Geist, A.; Kozhevnikov, V. N.; Distler, P.; John, J. Hydrophilic Sulfonated Bis-1,2,4-Triazine Ligands Are Highly Effective Reagents for Separating Actinides $(<\mathrm{scp}>\mathrm{iii}</ \mathrm{Scp}>$ ) from Lanthanides $(<\mathrm{scp}>\mathrm{iii}</$ Scp $>$ ) via Selective Formation of Aqueous Actinide Complexes. Chem. Sci. 2015, 6 (8), 4812-4821. https://doi.org/10.1039/C5SC01328C.

(23) Geist, A.; Müllich, U.; Magnusson, D.; Kaden, P.; Modolo, G.; Wilden, A.; Zevaco, T. Actinide(III)/Lanthanide(III) Separation Via Selective Aqueous Complexation of Actinides(III) Using a Hydrophilic 2,6-Bis(1,2,4-Triazin-3-Y1)-Pyridine in Nitric Acid. Solvent Extr. Ion Exch. 2012, $30 \quad$ (5), 433-444. https://doi.org/10.1080/07366299.2012.671111.

(24) Mincher, B. J.; Elias, G.; Martin, L. R.; Mezyk, S. P. Radiation Chemistry and the Nuclear Fuel Cycle. J. Radioanal. Nucl. Chem. 2009, 282 (2), 645-649. https://doi.org/10.1007/s10967-009-0156-x.

(25) Mincher, B. J.; Mezyk, S. P. Radiation Chemical Effects on Radiochemistry: A Review of Examples Important to Nuclear Power. Radiochim. Acta 2009. 
https://doi.org/10.1524/ract.2009.1646.

(26) Berthon, L.; Charbonnel, M.-C. Radiolysis of Solvents Used in Nuclear Fuel Reprocessing. In Ion Exchange and Solvent Extraction: A Series of Advances; Volume 19; Moyer, B. A., Ed.; Boca Raton: CRC Press, 2009; pp 429-513. https://doi.org/10.1201/9781420059700c8.

(27) Mincher, B. J.; Modolo, G.; Mezyk, S. P. Review Article: The Effects of Radiation Chemistry on Solvent Extraction 3: A Review of Actinide and Lanthanide Extraction. Solvent Extraction and Ion Exchange. 2009. https://doi.org/10.1080/07366290903114098.

(28) Pikaev, A. K.; Kabakchi, S. A.; Egorov, G. F. Some Radiation Chemical Aspects of Nuclear Engineering. Int. J. Radiat. Appl. Instrumentation. Part 1988. https://doi.org/10.1016/13590197(88)90260-3.

(29) Tripathi, S. C.; Ramanujam, A. Effect of Radiation-Induced Physicochemical Transformations on Density and Viscosity of 30\% TBP - n-Dodecane - HNO3 System. Sep. Sci. Technol. 2003. https://doi.org/10.1081/SS-120021626.

(30) Mossini, E.; Macerata, E.; Giola, M.; Brambilla, L.; Castiglioni, C.; Mariani, M. Physico Chemical Properties of Irradiated I-SANEX Diluents. Nukleonika 2015, 60 (4), 893-898. https://doi.org/10.1515/nuka-2015-0118.

(31) Mossini, E.; Macerata, E.; Giola, M.; Brambilla, L.; Castiglioni, C.; Mariani, M. RadiationInduced Modifications on Physico Chemical Properties of Diluted Nitric Acid Solutions within Advanced Spent Nuclear Fuel Reprocessing. J. Radioanal. Nucl. Chem. 2015, 304 (1), 395-400. https://doi.org/10.1007/s10967-014-3556-5. 
(32) Sugo, Y.; Izumi, Y.; Yoshida, Y.; Nishijima, S.; Sasaki, Y.; Kimura, T.; Sekine, T.; Kudo, H. Influence of Diluent on Radiolysis of Amides in Organic Solution. Radiat. Phys. Chem. 2007. https://doi.org/10.1016/j.radphyschem.2006.05.008.

(33) Sugo, Y.; Sasaki, Y.; Kimura, T.; Sekine, T. Attempts to Improve Radiolytic Stability of Amidic Extractants. In GLOBAL 2007: Advanced Nuclear Fuel Cycles and Systems; 2007.

(34) Sugo, Y.; Sasaki, Y.; Tachimori, S. Studies on Hydrolysis and Radiolysis of N,N,N',N'Tetraoctyl-3-Oxapentane-1,5-Diamide. $\quad$ Radiochim. $\quad$ Acta 2002. https://doi.org/10.1524/ract.2002.90.3_2002.161.

(35) Galán, H.; Núñez, A.; Espartero, A. G.; Sedano, R.; Durana, A.; de Mendoza, J. Radiolytic Stability of TODGA: Characterization of Degraded Samples under Different Experimental Conditions. Procedia Chem. 2012. https://doi.org/10.1016/j.proche.2012.10.033.

(36) Mincher, B. J.; Modolo, G.; Mezyk, S. P. Review: The Effects of Radiation Chemistry on Solvent Extraction 4: Separation of the Trivalent Actinides and Considerations for Radiation-Resistant Solvent Systems. Solvent Extraction and Ion Exchange. 2010. https://doi.org/10.1080/07366299.2010.485548.

(37) Ekberg, C.; Fermvik, A.; Retegan, T.; Skarnemark, G.; Foreman, M. R. S.; Hudson, M. J.; Englund, S.; Nilsson, M. An Overview and Historical Look Back at the Solvent Extraction Using Nitrogen Donor Ligands to Extract and Separate An(III) from Ln(III). Radiochim. Acta 2008, 96 (4-5), 225-233. https://doi.org/10.1524/ract.2008.1483.

(38) Magnusson, D.; Christiansen, B.; Malmbeck, R.; J.-P. Glatz. Investigation of the Radiolytic Stability of a CyMe4-BTBP Based SANEX Solvent. Radiochim. Acta 2009. 
https://doi.org/10.1524/ract.2009.1647.

(39) Galàn, H.; Munzel, D.; Núñez, A.; Müllich, U.; Cobos, J.; Geist, A. Stability and Recyclability of SO3-Ph-BTP for i-SANEX Process Development. In International Solvent Extraction Community (ISEC 2014; Würzburg, Germany, 2014; pp 137-143.

(40) Peterman, D.; Geist, A.; Mincher, B.; Modolo, G.; Galán, M. H.; Olson, L.; McDowell, R. Performance of an I-SANEX System Based on a Water-Soluble BTP under Continuous Irradiation in a $\gamma$-Radiolysis Test Loop. Ind. Eng. Chem. Res. 2016. https://doi.org/10.1021/acs.iecr.6b02862.

(41) Macerata, E.; Mossini, E.; Scaravaggi, S.; Mariani, M.; Mele, A.; Panzeri, W.; Boubals, N.; Berthon, L.; Charbonnel, M. C.; Sansone, F.; Arduini, A.; Casnati, A. Hydrophilic Clicked 2,6-Bis-Triazolyl-Pyridines Endowed with High Actinide Selectivity and Radiochemical Stability: Toward a Closed Nuclear Fuel Cycle. J. Am. Chem. Soc. 2016, 138 (23), 7232 7235. https://doi.org/10.1021/jacs.6b03106.

(42) Wagner, C.; Mossini, E.; Macerata, E.; Mariani, M.; Arduini, A.; Casnati, A.; Geist, A.; Panak, P. J. Time-Resolved Laser Fluorescence Spectroscopy Study of the Coordination Chemistry of a Hydrophilic CHON [1,2,3-Triazol-4-Y1]Pyridine Ligand with Cm(III) and Eu(III). Inorg. Chem. 2017, $56 \quad$ (4), 2135-2144. https://doi.org/10.1021/acs.inorgchem.6b02788.

(43) Ossola, A.; Macerata, E.; Mossini, E.; Giola, M.; Gullo, M. C.; Arduini, A.; Casnati, A.; Mariani, M. 2,6-Bis(1-Alkyl-1H-1,2,3-Triazol-4-Yl)-Pyridines: Selective Lipophilic Chelating Ligands for Minor Actinides. J. Radioanal. Nucl. Chem. 2018, 318 (3), 2013- 
2022. https://doi.org/10.1007/s10967-018-6253-y.

(44) Mossini, E.; Macerata, E.; Wilden, A.; Kaufholz, P.; Modolo, G.; Iotti, N.; Casnati, A.; Geist, A.; Mariani, M. Optimization and Single-Stage Centrifugal Contactor Experiments with the Novel Hydrophilic Complexant PyTri-Diol for the i-SANEX Process. Solvent Extr. Ion Exch. 2018, 36 (4), 373-386. https://doi.org/10.1080/07366299.2018.1507134.

(45) Mossini, E.; Macerata, E.; Brambilla, L.; Panzeri, W.; Mele, A.; Castiglioni, C.; Mariani, M. Radiolytic Degradation of Hydrophilic PyTri Ligands for Minor Actinide Recycling. $J$. Radioanal. Nucl. Chem. 2019, 322 (3), 1663-1673. https://doi.org/10.1007/s10967-01906772-7.

(46) Boubals, N.; Wagner, C.; Dumas, T.; Chanèac, L.; Manie, G.; Kaufholz, P.; Marie, C.; Panak, P. J.; Modolo, G.; Geist, A.; Guilbaud, P. Complexation of Actinide(III) and Lanthanide(III) with H4TPAEN for a Separation of Americium from Curium and Lanthanides. Inorg. Chem. 2017. https://doi.org/10.1021/acs.inorgchem.7b00603.

Drader, J. A.; Boubals, N.; Camès, B.; Guillaumont, D.; Guilbaud, P.; Saint-Louis, G.; Berthon, L. Radiolytic Stability of: N, N -Dialkyl Amide: Effect on Pu(IV) Complexes in Solution. Dalt. Trans. 2018. https://doi.org/10.1039/c7dt03447d.

(48) Wall, T. F.; Jan, S.; Autillo, M.; Nash, K. L.; Guerin, L.; Naour, C. Le; Moisy, P.; Berthon, C. Paramagnetism of Aqueous Actinide Cations. Part I: Perchloric Acid Media. Inorg. Chem. 2014. https://doi.org/10.1021/ic402371x.

(49) Taylor, J. R. Chapter 3. Propagation of Uncertainties. In An introduction to error analysis: the study of uncertainties in physical measurements; 1997. 
G.R. Fulmer; A.J.M. Miller; N.H. Sherden; H.E. Gottlieb; A. Nudelman; B.M. Stoltz; J.E. Bercaw; Goldberg, K. I. NMR Chemical Shifts of Trace Impurities: Common Laboratory Solvents Relevant to the Organomettalic Chemist. Organometallics 2010.

(51) Mossini, E.; Macerata, E.; Brambilla, L.; Panzeri, W.; Mele, A.; Castiglioni, C.; Mariani, M. Radiolytic Degradation of Hydrophilic PyTri Ligands for Minor Actinide Recycling. $J$. Radioanal. Nucl. Chem. 2019, 322 (3), 1663-1673. https://doi.org/10.1007/s10967-01906772-7.

(52) Galán, H.; Zarzana, C. A.; Wilden, A.; Núñez, A.; Schmidt, H.; Egberink, R. J. M.; Leoncini, A.; Cobos, J.; Verboom, W.; Modolo, G.; Groenewold, G. S.; Mincher, B. J. Gamma-Radiolytic Stability of New Methylated TODGA Derivatives for Minor Actinide Recycling. Dalt. Trans. 2015. https://doi.org/10.1039/c5dt02484f. 
TOC (size requested by the journal)

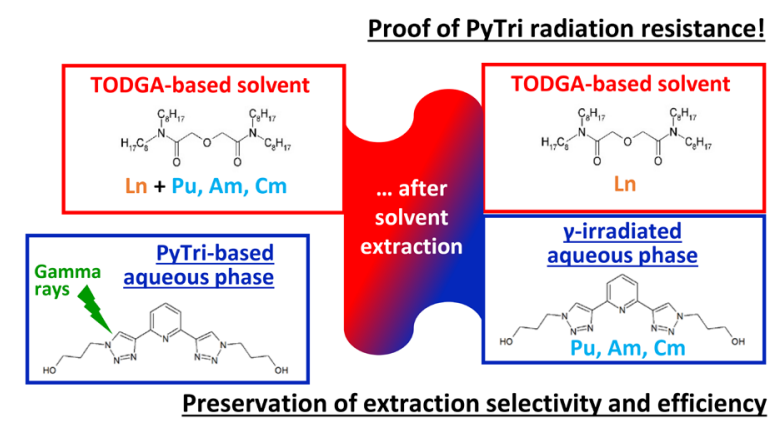

(TOC enlargement for your readability)

\section{Proof of PyTri radiation resistance!}

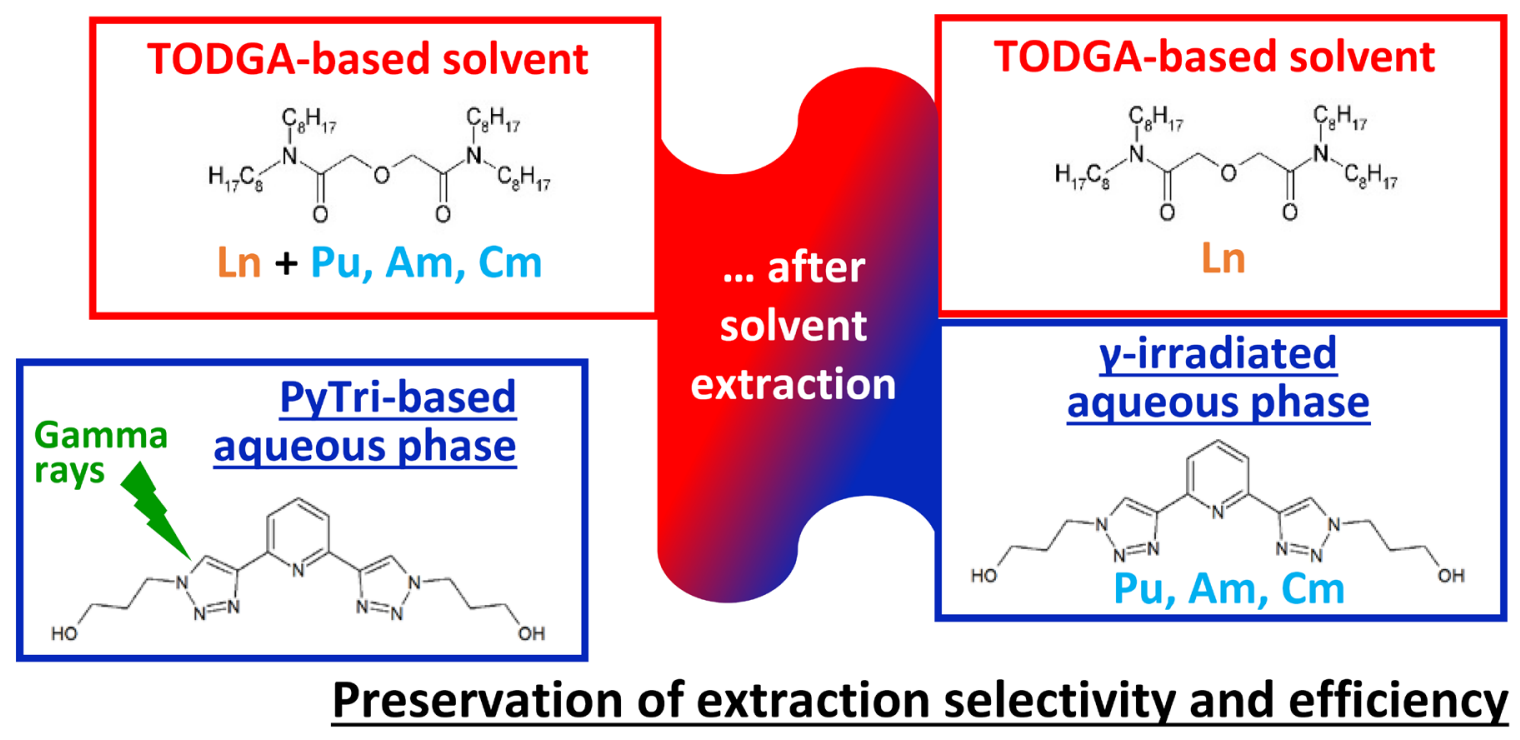

